DOI

http://dx.doi.org/10.1590/2236-463320161208

Cosmopolites of the Hidden

Atlantic: the "africans" Daniel

Botefeur and his personal slave

Robin Botefeur in Cuba

\title{
Cosmopolitas del Atlántico esclavista: los "africanos" Daniel Botefeur y su esclavo de confianza Robin Botefeur en Cuba
}

\section{Michael Zeuske}

Universität zu Köln de Colonia (UniversitaetzuKoeln/GlobalSouth Studies Center - GSSC). michael.zeuske@uni-koeln.de
Resúmen

El artículo trata de la historia micro de dos hombres entre Africa y las Américas (Cuba): un médicoy capitán/negreronacidoen Alemaniaysu esclavonacidoen la regiónoel hinterland delGambia. Ambostienen saberes extraordinarios del Atlántico esclavista (hidden Atlantic)"desdeabajo", sobre todo sobre Africa. El médico se hace comerciante rico con estos conocimentosy se casa dentro de los marcos de una viejaélite de Cuba (no sin conflictos). Su esclavo y cosmopolita africano trata de adquirir la libertad (encontra de su amo cosmopolita). El artículo demuestra la actuación de ambos mediante tres casos legales.

\section{Abstract}

The article deals with the microstory of two men between Africa and the Americas (Cuba): a doctor and captain/ slaver born in Germany and his slave born in the region or the hinterland of the Gambia river. Both haveextraordinaryknowledgeof the slave Atlantic (hidden Atlantic)"from below", especially on Africa. The doctor becomes a rich merchant with this knowledge and marries within the framework of an old elite of Cuba (not without conflicts). His slave and African cosmopolite is trying to acquire hisfreedom (againsthis cosmopolitan master). Thearticleshows theagency of both by three legal cases.

Palabras-Clave

Atlántico, História Ibérica Trafico Negrero, Cuba Tribunal de Comercio.

Keywords

Hidden Atlantic, New Iberian Atlantic of the Nineteenth Century, Trafficking and Smuggling of Human Bodies, New Social History of Law, Cases Before the Court of Commerce of Havana, Captains, Merchants and Slavers/ Negreros. 
Declaración del esclavo Roberto. La Habana, 2 de Marzo de 1818. In: Archivo Nacional de Cuba (ANC), Escribanía de Daumy, legajo (leg.). 370, no. 1 (1818): Daniel Botefeur, contra su esclavo Roberto sobre hurto, f. 9r-13r, aqui f. 10v.

MURRAY, David. Odious Commerce: Britain, Spain and the Abolition of the Cuban SlaveTrade. Cambridge: Cambridge University Press, 1980; NEEDELL, Jeffrey D. The Abolition of the Brazilian SlaveTradein 1850:Historiography, Slave Agency and Statemanship. In: Journal of Latin American Studies, Vol. 33, no. 4 (2001), p. 681-712; BERBEL, Márcia; MARQUESE, Rafael; PARRON, Tâmis. Escravidão e política: Brasil e Cuba, c. 17901850. São Paulo: Hucitec, 2010

3

Hubo, por los menos, cuatro categorías fundamentales de actores que abarca el concepto de "negrero" (en su tiempo nadie se atrevía de decirles esta palabra en la cara; sólo se la usaba por detrás): capitanes (y oficiales, médicos de los barcos negreros), dadores de capital (armadores, grandes comerciantes) factores/ cargos (en África, en los barcos) y traficantes/ contratadores (que repartían los cuerpos humanos esclavizados con nombres esclavos en los puertos americanos (incluyo, los colegas brasileños me lo van a perdonar, Brasil a "América"), véase:COGGESHALL,George.Chapter IX:Voyage to St. Bartholomew, St. Thomas, Santa Cruz and Porto Rico, in the Years 1830 and 1831. In: COGGESHALL, Voyages to various parts of the world: made between the years 1800 and 1831; selected from his $\mathrm{ms}$. journal of eighty voyages. New York: D. Appleton \& Company, 1853 (2nd edition), p. 241-273; ORTEGA, José Guadalupe. Cuban Merchants, Slave Trade Knowledge, and the Atlantic World, 1790s-1820s. In: Colonial Latin American Historical Review Vol. 15:3 (2006), p. 225-251; ZEUSKE, Michael. Die Upper Class der transatlantischen Sklaverei: Faktoren, Kapitäne und Negreros [La clase alta de la esclavitud transatlántica: factores, capitanes y negreros]. In:ZEUSKE, Sklavenhändler, Negreros und Atlantikkreolen. Eine Weltgeschichte des Sklavenhandels im atlantischen Raum [Comerciantes deesclavos, negrerosyCriollosdel Atlántico. Una historia global del tráfico negrero enelespacioatlántico],Berlin/Boston:deGruyter Oldenbourg, 2015, p. 206-239; ZEUSKE, "In den Amerikas. Sklavenmärkte und Sklavenhändler - Profiteure, Großkaufleute, Schiffsausrüster und Negreros" [En las Américas. Mercados de esclavosytraficantes deesclavos-acaparadores, armadores y negreros]. In: Ibidem, p. 240-269.

4

Sobre este Tribunal (que existía por lo menos hasta 1880) hay poca investigación sistemática. En la perspectiva de hoy era un cuerpo jurídico especial para las grandes empresas que tenía la tarea tácita de "legalizar lo ilegal" (a partir de la abolición de la trata en 1820), véase: PÉREZ MURILLO, María Dolores, El pensamiento esclavista del Tribunal de Comercio de la Habana (año de 1841). In: SOLANO, Francisco; GUIMERÁ, Agustín (eds.). Esclavitud y derechos humanos. La lucha por la libertad del negro en el siglo XIX. Madrid: Consejo Superior de Investigaciones Científicas, 1990, p. 407-414 "p.[ar]a juntar el cap.[ital] de su libertad"1

Esta es una historia micro de dos hombres en tiempos de grandes cambios. En las historias de las esclavitudes inglesa y norteamericana, el siglo XIX es conocido como "age of abolition" a partir de 1808, mientras las historiografías de idiomas ibéricos, tanto portugués comocastellano (o gallego, vasco, catalán), no son tan optimistas. Sí hubo actos de abolición de la trata, en ambos casos varios, pero la trata ilegal de cuerpos humanos demoró en Brasil hasta más o menos 1851 y en el imperio insular de España, sobre todo hacia Cuba, hasta más o menos $1873^{2}$. Por eso llamo al período de 1820 hasta 1880 la época del hidden Atlantic.

En el marco de la historia micro, en los años 1815, 1816 y 1818 - a las alturas del comercio libre (free trade) de "negros" hacia Cuba y Puerto Rico (est. 1789, abolido en 1820) - pasaban cosas muy raras entre negreros dela Habana. En estegrupo heterogéneo los grandes invertidoreseran llamados capitalistas en el lenguaje contemporáneo ${ }^{3}$. Todas estas cosas raras se presentaban como casos jurídicos ante el llamado Tribunal de Comercio en la Habana ${ }^{4}$. En dos de los tres casos era involucrado directamenteunhombrenacidoenHannover, Alemania-DanielBotefeur(1770?1821). Los otros protagonistas eran un gran comerciante de esclavos hispano-cubano(AntonioEscoto ${ }^{5}$ ), unfactor(enespañolcubanomongo ${ }^{6}$ ) decolorcon padreescocésymadreafricana,John/JuanOrmond,conocido como mongo John, y un esclavizado del cual sólo conocemos su nombre esclavo - Robert Botefeur.

A mísiempre, lo confieso aquí, la voz directa de los esclavizados ("subalternos"- una palabra muy fea, pero útil cuando se trata de esclavizados aunque uno no se ve como partidario de la corriente cultural de estudios subalternos) me ha interesado más que la palabra directa de los esclavizadores. Pero muchas veces vale la pena "oír"la voz de los esclavizadores, porque alumbran también el destino de los esclavizados. Todos sabemos que "oír" es simbólico, porque sólo podemos leer las voces o descifrar el "lenguaje" visual".

Laactuación de Daniel Botefeur demuestra a primera vista la tesis de Joseph Miller de la "marginalidad" (marginality) ${ }^{8}$ de comerciantes de esclavos en cuanto a la sociedad a la cual suministran esclavos (en este caso, Cuba). Y eso en dos dimensiones. Primero, entran en la sociedad como personas de bajo estatus y durante su actuación suben más y más hacía los grupos más altos de la élite. Muchas veces se auto declaran cosmopolitas. Eso lo llamo el fenómeno del "conde de Monte Cristo". Llegado a estas alturas dehaberseenriquecido,forman, porlosmenosen el sigloXIX, parte de una élite que transforma una sociedad dada hacia una sociedad de modernidad esclavista a base de la Second Slavery con sus propias formas de capitalismo esclavista (cómo el sur de Brasil, Cuba, el sur de EEUU, Puerto Ricoy Surinam, así como, parcialmente, Martinique, Guadeloupey Cayenne). Cuandollevaban suscapitales haciala metrópoliEspañaerantambién conocidos bajo el nombre de "indianos". ${ }^{10}$

La actuación activa de Roberto Botefeur, el esclavizado, demuestra, aunque tenemos muchísimo menos "voz" de él, que además pasó por el oído, el cerebro y la mano del escribiente, que era un actor, valga la repetición, un hombre muy activo que trataba usar el espacio legal (y tal vez ilegalquenosabemosaún) dela sociedadmoderna esclavistaenCuba.Eso se llama agency de un esclavizado. Veremos. 
Todavía no he podido averiguar si éste Escoto es el padre o uno de los relativos del famoso colector José Augusto Escoto (1864-1934) de Matanzas (lo quéesmuyprobable),véase:ESCOTO,JoséAugusto, collector. José Augusto Escoto Cuban history and literature collection, ca. 1574-1922 (inclusive), ca. 1715-1850 (bulk). In:

HoughtonLibrary, HarvardUniversity, Cambridge, Mass (Escoto Papers: http://oasis.lib.harvard.edu/ oasis/deliver/ hou00236(Acessoem15.Mai2015); PAQUETTE,RobertL.;DORSEY,JosephC.,TheEscoto Papers and Cuban Slave Resistance. In: Slavery \& Abolition Vol. 15:3, December 1994, p. 88-95.

6

FRANCO, José Luciano. Los mongos de la costa de África. In: FRANCO, Comercio clandestino de esclavos, La Habana: Editorial de Ciencias Sociales, ${ }^{3} 1996$, p. $178-202$.

7

ARAUJO, Ana Lucia, Les représentations de l'esclavage dans les gravures des relations Voyage pittoresque et historique au Brésil (1834) de Jean-Baptiste Debret (1768-1848) et Deux Années au Brésil (1862), de François-Auguste Biard (1799-1882). In: Canadian Journal of Latin American and Caribbean Studies 59, no. 30 (2005), p. 161-183.

8

MILLER, Joseph C., Defining Slaving as a Historical Strategy. In: MILLER, The Problem of SlaveryasHistory.AGlobal Approach.NewHaven: Yale University Press, 2012, p. 29-35.

9

TOMICH, Dale W. The, Second Slavery': Bonded LaborandtheTransformations oftheNineteenthcentury World Economy. In: RAMÍREZ, Francisco O. (ed.). Rethinking the Nineteenth Century: Contradictions and Movement. New York: Greenwood Press, 1988, p. 103-117; TOMICH. Through the Prism of Slavery. Labor, Capital, and World Economy. Boulder [etc.]: Rowman \& Littlefield Publishers, Inc. 2004; TOMICH \& ZEUSKE (eds.).The Second Slavery: Mass Slavery, World-Economy, andComparativeMicrohistories, 2 vols. Binghamton: Binghamton University, 2009 (=special issue; Review: A Journal of the Fernand Braudel Center, Binghamton University XXXI, no. 2 \& 3, 2008); LAVIÑA, Javier; ZEUSKE (eds.). The Second Slavery. Mass Slaveries and Modernity in the Americas and in the Atlantic Basin. Berlin; Muenster; New York: LIT Verlag, 2014 (Sklaverei und Postemanzipation/ Slavery and Postemancipation/ Esclavitud y postemancipación; Vol.6);TOMICH. The Order of Historical Time: The Longue Duree and MicroHistory. In: LEE, Richard (ed.). The Longue Duree and World-Systems Analysis. Albany: State University of New York Press, 2012, p. 9-33.

\section{0}

RODRIGOYALHARILLA,Martín.From Periphery to Centre: Transatlantic Capital Flow, 18301890.In: LEONARD, Adrian; PRETEL, David (eds.). The Caribbean and the Atlantic World Economy.Circuitsoftrade,moneyandknowledge, 1650-1914. London: Palgrave Macmillan, 2015 (Cambridge Imperial and Post-Colonial Studies Series), p. 217-237.
Además, la historia micro de Daniel Botefeur y su esclavo preferido Roberto, como ejemplo en cuanto a actores sociales de la esclavitud y la trata (los negreros y sus esclavizados, normalmente tratados - los últimos-como"víctimas"o"commodities"), demuestra perfectamenteque el cosmopolitismo, un hábito cultural al cual recurren frecuentemente historias de grupos de élite social (la mayoría hasta hoy sin que se mencione la esclavitud y la trata), es más bien y más originalmente un hábito cultural, una experiencia de vida real, de los actores de la Atlantic slavery (esclavizados, esclavizadores y su personal) ya desde el comienzo de la trata transatlántica masiva (siglo XVI). ${ }^{11}$

\section{Los dos hombres Botefeur y el Atlántico eslavista}

De Daniel Botefeur sabemos mucho más que sobre Roberto Botefeur. ${ }^{12}$ Me acuerdo como hoy que en un día lindo en la Habana, era el 30 de marzo de 2012, encontré en la famosa sala de lectura del Archivo Nacional de Cuba la testamentaria y el certificado de defunción de Daniel Botefeur. ${ }^{13}$ En realidad, yo estaba en búsqueda de Ramón Ferrer, el capitán del barco negrero Amistad. Pero me electrificaba la frase“D. Daníel Botefeur Natural de Hanover en Alemania vecino de esta [Matanzas]"14 en su testamento. Como se podía ver en el testamento - un hombre riquísimo para su tiempo, un verdadero Monte Cristo. ¿Pero un alemán de Hannover (una ciudad que tiene la fama de ser un poco aburrida) como amo de muchos esclavos en Cuba, ex mongo y a la vez un comerciante muy rico? Todos sabemos que nacionalidad en aquel entonces no era muy fluyente, todavía apenas existían Estados nacionales (tal vez en Inglaterra, Dinamarca y Portugal algo como un nacionalismo monárquico). Era más bien la"naturalidad" que contaba. Pero bueno, el documento dice claramente "natural de Hanover en Alemania".

Empecéa buscar no sólo por Ramón Ferrery sus otros barcos (allado de la goleta Amistad), sino también por Daniel Botefeur o, mejor dicho Dr. Daniel Botefeur (también: Botefour, Botifeur, Botefur, Botefer, Botefú, Buteffeur, etc.). Además de su vida individual como comerciante de esclavizados, es decir, negrero, me parecía importante cómo representante de los comienzos de la globalización transcultural de la trata después de la abolición británica y estadounidense en 1808 y las aboliciones de la trata transatlántica portuguesa (al norte del ecuador 1817/1818) y española (1820). Eran cosmopolitas del Atlántico oculto.

Para dar una idea breve de la life history de Daniel Botefeur: nació más o menos alrededor de 1770 en el reino de Hannover (por lazos monárquicos unido con la corona de Gran Bretaña); parece que hizo una carrera como cirujano. Hasta ahora no he encontrado qué este hombre hizo en sus primeros 30 años. Primero pensé que era judío alemán (por el nombre Daniel)-nada; después lo busquéenfuentes dehugonotes alemanes (por el apellido qué parece francés; en alemán es posible también la forma de Boteför o Böteför) - nada; la única huella es el apellido de alemanes del norte que hay también en la historia comercial de Inglaterra (todos luteranos). Alrededor de 1800 Daniel Botefeur apareció en los establecimientos ingleses en Bunce Island/ Gambia*15 (primero como cirujano/ médico) y después en el río Pongo (sobre todo en las fuentes de la obra de Mouser ${ }^{16}$ ). Para decir también algo de Robin o Roberto Botefeur - fue en el Gambia que Daniel Botefeur lo compró cómo su primer esclavo. Eso es la única in- 
Menciono aquí sólo el caso de los grupos de comerciantes y sus networks de Portugal y de Gran Bretaña y los mundos del Océano indico criollo, así como del Atlántico inglés: ROSA, Fernando. The Portuguese in the Creole Indian Ocean: Essays in Historical Cosmopolitism. Basingstoke/ New York: Palgrave Macmillan, 2015; Sheriff, Abdul. Dhow Cultures of the Indian Ocean: Cosmopolitanism, Commerce and Islam. New York: Columbia University Press, 2010; GESTRICH,Andreas;SCHULTEBEERBÜHL,Margrit (eds.).Cosmopolitan Networksin Commerceand Society 1660-1914. London: German Historical Institute, 2011 (German Historical Institute London Bulletin Supplement No. 2. Disponível em:http://www.ghil.ac.uk/fileadmin/redaktion/ dokumente/bulletin/GHIL\%20Bulletin\%20 Supplement\%202\%20\%282011\%29.pdf (31 enero de 2016))). Hay otros trabajos que a primera vista parecen tratar "cosmopolitismo sin esclavitud y trata", pero en los trabajos es imposible ocultarlo: YÁÑEZ, César. Los negocios ultramarinos de una burguesía cosmopolita. Los catalanes en las primeras fases de la globalización, 1750-1914. In: Revista de Indias Vol. LXVI, núm. 238 (2006), p. 679-710.

12

AUPIN, Guy (ed.). Africains et Européens dans le monde atlantique XVe-XIXe siècle. Rennes: Presses Universitaires de Rennes, 2014.

13

Autos.Testamentaria delDr.Dn.Daniel Botefeur. In:ArchivoNacional deCuba(ANC), Escribanía de Luis Blanco, legajo (leg.) 405, número (no). 4.

14

Copia original del testamento, Matanzas, 9 de Junio de 1821. In: Ibidem, folio (f.), 9 recto (r)11 verso (v), la cita en f. 9 r.

15

HANCOCK, David J. Slaving: Bance Island's 'General Rendevous'. In: HANCOCK. Citizens of theWorld.Londonmerchantsandtheintegration of the British Atlantic community, 1735-1785. Cambridge:Cambridge University Press, 1995, p. 174-220.

16

HANCOCK, David J. Slaving: Bance Island's 'General Rendevous'. In: HANCOCK. Citizens of theWorld.Londonmerchantsandtheintegration of the British Atlantic community, 1735-1785. Cambridge: Cambridge University Press, 1995, p. 174-220.

17

En cuanto a los castings corporales de los médicos, véase: KRIKLER, Jeremy, A Chain of Murder in the Slave Trade: A Wider Context of the Zong Massacre. In: International Review of Social History Vol 57:3 (December 2012), p. 393 415; BRIGHT, Richard, Richard Bright Journal, September and October 1802. In: MOUSER, Bruce L. (ed.). Guinea Journals: Journeys into Guinea-Conakry during the Sierra Leone Phase, 1800-1821. Washington: University Press of America, 1979, p. 66; MOUSER, Trade, Coasters and Conflict in the Rio Pongo from 1790 to 1808. In: Journal of African History 14 (1973), p. 45-64; formación qué tenemos hasta ahora de la vida de Robin Botefeur antes de 1818. ${ }^{17}$ Hipotéticamente podemos imaginar que llegó desde el interior al deltadelGambiaen una caravanadeesclavizadoscomoladescribeMungo Park. ${ }^{18}$ También podemos imaginar qué el muchacho ojoven hombre con su nombre africano que más tarde es llamado Robert o Robin (entre británicos) o Roberto (entre ibéricos, pero también se usaba Robin), tenía experiencias devidadeunAtlánticocosmopolita“desdeabajo"(comoBenjamin Lawrance los describe para los hombres jóvenes y niños implicados en el "caso" Amistad). ${ }^{19}$

Sea como sea, parece qué Daniel Botefeur invirtió sus ganancias cómo médico en un barco de transportación costera (por ejemplo ganado para barcos negreros). La parte muy interesante viene en 1808 , cuando los ingleses europeos habían abolido la trata en sus establecimientos en la región del Gambia y Bunce Island..$^{20}$ ¿Qué debía pasar con los barcos de la trata, con todas las experiencias adquiridas de la complicada trata de cuerpos humanos en la costas africanas? Normalmente se hacen alusión a los pioneros del hidden Atlantic, es decir, el lado atlántico (y el rol de comerciantesestadounidensesqueactuaronbajolaumbrela delcomerciode café: Ios Frazier, los Wolf, los Booth y los Mitchell). ${ }^{21}$ Estos eran indudablemente importantes, pero hay un lapso entre 1808 y 1815 , y hay la cuestión - ¿por qué la trata y los comerciantes esclavistas con sus barcos se mueven hacía el río Pongo y los ríos de Guiné (en especial: rivers Pongo and Nunez to the north and Gallinas and Cape Masanagu to the south of Freetown)? De la vida de dos actores importantes de la trata - D. Botefeur y John Ormond (jr.) - se sabe que se encontraron en Bunce Island alrededor de 1808 y que pasaron al río Pongo. Parece que Botefeur también era implicado en el plan de los negreros de la Habana de formar una base en Gallinas, "the notorious slave mart of the Northwest Coast of Africa "(mapa). ${ }^{22}$ Yo creo que la razón es, al lado de las experiencias especiales de factores (mongos)/comerciantes estadounidenses (cómo los hermanos Faber - Jacoby Paul-de Baltimore que habían hecho trata entre Charleston y Sierra Leona hasta 1808 y la continuaron el Río Pongo después, o Peter Harmony ${ }^{23}$ ) que la parte más importante en el trasfondo del nuevo Atlántico ibérico eran las nuevas alianzas entre comerciantes deesclavos portuguesesyespañoles-cubanos, con centro en Caboverde (Praia y otros lugares) y con mucho personal de criollos del Atlántico africano-portugués (para mencionar los conceptosportugueses másimportantes portodaÁfricaatlántica:baquianos, grumetes, pombeiros, panyarrs(delverbo"apanhar"), quimbares,sertanejos, lançados, tangomãos) ${ }^{24}$. Todo eso sobre una base siempre existente en África de personal y saberes "portugueses" de la trata (en toda la época de la Atlantic slavery 1460-1873). También quedaron bastante criollos del Atlántico británicos (como mongo John, los Faber y familias de color de Nova Scotia). ${ }^{25}$ Eso demuestra que - a pesar de la hegemonía de estudios anglosajonessobrelatrata (p.ej.:www.slavevoyages.org)-quelapenínsula ibérica, las colonias (o ex colonias) ibéricas en África occidental, América y el Caribe eran los territorios de demanda más importantes de la trata atlántica - también después de las independencias políticas de los años 1822-1830 (Brasil y las colonias continentales de España en América). ${ }^{26}$ Para pasar a lo largo del siglo XIX hasta 1851-1873 (fin de la trata hacia Brasil primero, y para Cuba después): en el llamado periodo del hidden Atlantic, otro término para el nuevo Atlántico ibérico, pasaron todavía 2-3 millones de esclavizados africanos a América, sobre todo a Brasil y Cuba. ${ }^{27}$ 
MOUSER,ThéophilusConneau:TheSaga ofaTale. In: History in Africa 6 (1979), p. 97-107; MOUSER, The Baltimore/Pongo Connection: American Entrepreneurship, Colonial Expansionism, or African Opportunism? In: The International Journal of African Historical Studies Vol. 33, No. 2 (2000), p. 313-333; MOUSER, A History of Rio Pongo: Time for a New Appraisal, In: History in Africa 37 (2010), p. 329-354; MOUSER. American Colony on the Rio Pongo: The War of 1812,

ContinuingSlaveTrade,andPlansforaSettlement of African Americans, 1810-1830. Trenton: Africa World Press, 2014

18

PARK, Mungo. Chapter XIX. In: PARK. Travels in the Interior Districts of Africa Performed under the Direction and Patronage of the African Association, in the Years 1795, 1796, and 1797. London: Printed by W. Bulmer and Company, 1800 ( $4^{\text {th }}$ edition), p. 227-238

\section{9}

LAWRANCE, Benjamin. A Full Knowledge of the Subject of Slavery': The Amistad, Expert Testimony, and the Origins of Atlantic Studies. In: Slavery \& Abolition Vol. 36:2 (2015), p. 298-318; Lawrance.LaAmistad's'Interpreter'Reinterpreted: James Kaweli Covey's Distressed Atlantic ChildhoodandtheProductionofKnowledgeabout Nineteenth-Century Sierra Leone. In: Schwarz, Suzanne;Lovejoy, PaulE.(eds.).Slavery, Abolition and the Transition to Colonialism in Sierra Leone. Trenton: Africa World Press, 2014, p. 215-256; LAWRANCE.Amistad'sOrphans:AnAtlanticStory of Children, Slavery, and Smuggling. New Haven and London: Yale University Press, 2014.

20

O'MALLEY, Gregory. The Intercontinental Slave Trade of British America, 1619-1807. Chapel Hill: The University of North Carolina Press, 2014.

21

JOHNSON, Sherry. The Rise and Fall of Creole Participation in the Cuban Slave Trade, 17891796. In: Cuban Studies 30 (1999), p. 52-75; MARQUES, Leonardo. A participação norteamericana no tráfico transatlântico de escravos para os Estados Unidos, Cuba e Brasil. In: Historia: Questões \& Debates, Curitiba, no. 52 (jan./jul. 2010),p.91-117;GRADEN,DaleT.Oenvolvimento dosEstadosUnidosnocomérciotransatlânticode escravos para o Brasil, 1840-1858. In: Afro-Ásia, Salvador, n.35 (2007), p. 9-35; HORNE, Gerald. O sul mais distante. Os Estados Unidos, o Brasil e o tráfico de escravos africanos. São Paulo: Companhia das Letras, 2010; GRADEN, U.S. Involvement in the Transatlantic Slave Trade to Cubaand Brazil.In:GRADEN.Disease, Resistance, and Lies. The Demise of the Transatlantic Slave Trade to Brazil and Cuba. Baton Rouge: Louisiana State University Press, 2014, p. 12-39.

\section{2}

Véase: Contrata celebrada entre los Sres. D.n José Ricard, D.n Juan y D.n Antonio O: Farril, D.n Juan Espinoza, y D.n Cornelio Souchay por una parte, y D.n Jacobo Faber por otra, para Establecer una Factoria en la costa septentrional de Africa en el Puerto de Gallinas, por el termino de dos años contado desde eldia dela llegada de Faber a dcho destino. In: ANC, TC, Leg. 192,
Conel boom del cafédespués delasguerrasnapoleónicas, alrededor de 1815,DanielBotefeury RobertoBotefeurdebenhabersemovidoaCuba (La Habanay Matanzas). Roberto siempreera el esclavo personal de Daniel (en alemán: Leibsklave, algo cómo esclavo de cuerpo). Si seguimos a su testamento, Daniel Botefeur casó con“"D.a. María del Sacramento Romayy Navarrete" 28 , compró dos cafetales en las afueras de Matanzas, fundó una casa comercial por su nombre en La Habana ${ }^{29}$ y otra con un comerciante estadounidense (John S. Latting) en Matanzas ${ }^{30}$ y compró también dos haciendas de mar (territorios en la costa cerca de Matanzas - comprados en vista de la abolición del comercio "libre" de esclavos hacía las colonias españolas). Parece que Daniel Botefeur era uno de los fundadores de un sistema de negocios que reunía tanto grupos de comerciantes portugueses y de comerciantes españoles (basados en Cuba, Cádiz y Barcelona ${ }^{31}$ ), y el grupo de factores y médicos esclavistas británicos y estadounidenses. Además actuó en La Habana y en Matanzas, es decir en el espacio social, político y cultural de la élite negrera (más bien españoles y extranjeros naturalizado ${ }^{32}$ ) y esclavista (más bien hacendados cubano-españoles cómo Francisco de Arango) de Cuba, es decir en la famosa Cuba grande, cómo actor y representante de un nuevo estilo de capitalismo atlántico (juntoconotroalemán:CornelioSouchay, un especuladorfinanciero ${ }^{33}$ ).En nuestro contexto eso significa: cosmopolita con formación científica, con excelentes relacionesacolegasnorteamericanos, inglesesysuscriollos del Atlántico en África. Eso significa también: D. Botefeur era duro contra la élite tradicional, sobre todo contra la élite comercial esclavista tradicional de La Habana/ Matanzas (los Cuesta Manzanal ${ }^{34}$, los Madrazo ${ }^{35}$, los Escoto, etc. - la "oligarquía negrera" de José Luciano Franco $\left.{ }^{36}\right)$, pero también contra los derechos tradicionales de los esclavizados (cómo veremos más abajo). ${ }^{37}$

\section{Los casos ante el Tribunal de Comercio}

Antes de tratar en concreto los casos quiero demonstrar una lista de barcosnegreros, capturadosalrededorde 1815,es decir,muytemprano, de barcos ingleses. ${ }^{38}$ La lista es un documento formal del Estado español para las deliberaciones con Gran Bretaña sobre compensaciones de los comerciantes"españoles"(preparativo al tratado de 1817 sobre la abolición de la trata a partir de 1820). Lo que demuestra la lista es que en los años entre 1808 y 1818 hubo prácticamente una explosión de la trata entre Cuba y África. Daniel Botefeur ya aparece como "español"y también sus colegas de la trata y, de vez en cuando, adversarios de la élite comercial tradicional, aparecen en esta lista con el título "Reclamaciones de varios comerciantes de la Ysla de Cuba" (1817): ${ }^{39}$
D. Juan Madrazo (4 barcos $\left.{ }^{[40}\right]$ )
D. Jose Garcia Alvarez (4)
D. Ysidro Ynglada (1)
D. Francisco Bengochea (1)
S.res Pié y Comp.a (1)
D. Jose Carrera (1)
D. Jose Estaletta y otros (1)
D. Antonio Escoto (4)
D. Pedro Giral (1) 
no. 6 (1822); Faber (Jacobo): “D.n Jacobo Faber, contra D.n Martin Zabala". In: ANC, TC, Leg. 178, no. 6 (1822), f. 7r-8v (también: Ibidem, Real Consulado (RC), leg. 192, núm.6); la cita es de: CONNEAU,Theophilus.Chapter $66^{\text {th }}$.Description of Gallinas. In: CONNEAU. A Slaver's Log Book, or 20 Years Residence in Africa. The Original 1853 Manuscript by Captain Theophilus Conneau. Englewood Cliffs: Prentice Hall, 1976, p. 246248, aquí p. 246 (1836-1837); para el trasfondo véase:REDIKER,Marcus.Origins.In:REDIKER.The AmistadRebellion:AnAtlanticOdysseyofSlavery and Freedom. New York: Viking, 2012, p. 13-63 (mapa de la gran región en p. 23; LAWRANCE. TheOriginsofAmistad'sOrphans.In:LAWRANCE. Amistad's Orphans ... p. 47-87.

23

O'BRIEN, William Patrick. McCoy, Waldo, and Smith. A Case Study in International Trade. In: O'BRIEN. Merchants of Independence: International Trade on the Santa Fe Trail, 1827-1860. Kirksville: Truman State University Press, p. 145-167.

\section{4}

Que juegan su papel también en la otra factoría de cubano-españoles en Onim (Lagos; hoy Nigeria), véase: Representación [copia original] de Sebastian Martin de Rojas [apoderado]. In: AGl, Ultramar, 35, n.15, Madrid, ... de Agosto de 1820: Exped.te sobre que a la Casa Social Titulada Cuesta Manzanal y hermanos en la Isla de Cuba se le conceda el permiso para poder transportar 1600. negros que tenia comprados para sus hacienda, antes del tratado hecho con el Rey de Inglaterra, Madrid 5. de Oct.re de 1820, f. 609r-614r, aquí f. 609v-610r; véase también: ZEUSKE. Versklavte, Sklavereien und Menschenhandelaufdemafrikanisch-iberischen Atlantik [Esclavizados, esclavitudes y trata de cuerpos humanos en el Atlántico africanoibérico]. In: ZEUSKE. Sklavenhändler, Negreros und Atlantikkreolen ..., pp. 296-364; véase también: LIBERATO, Carlos F. Money, ClothCurrency,Monopoly, andSlaveTradein the Rivers of Guiné and the Cape Verde Islands, 1755-1777. In: EAGLETON, Catherine; FULLER, Harcourt; PERKINS, John (eds.). Money in Africa. London: The British Museum, 2009, p. 9-19.

25

GATES Jr., Henry L. Were There 'Mulatto' Slave Traders? 100 Amazing Facts about the Negro: A father-son story illustrates dynamics of the trade in humans. Disponível em: http:// www.theroot.com/articles/history/2013/10/ mulatto_slave_traders_who_were_they.html(20. February 2016)). Hay también una lista „White Slave Dealers at Galinhas, 1806-49", véase: JONES, Adam. From Slaves to Palm Kernels. A History of the Galinhas Country (West Africa) 1730-1890. Wiesbaden: Steiner Verlag, 1983 (Studien zur Kulturkunde; 68), p. 43; véase la presentación de un hombre qué era mongo en fuentes oficiales: Archivo Histórico Nacional (AHN) Madrid, Sección de Estado, Correspondencia entre la Capitanía General de Cubayla Primera Secretaría de Estado sobre la introducción de esclavos (1817-1873), 2 vols., Madrid: AHN, 1995 (mecanografiado, comp. León-Tello, P.), t. I, p. 25-26: El barco Two Friends [es decir, Dos Amigos - M.Z.], "cuyo
D. Francisco Comas (1)
D. Salvador Martiartu (2)
D. Pablo Samas (1)
D. Alonso Benigno Muñ.z [Muñoz] (1)
D. Juan Jose Sangron.z [Zangroniz] (2)
D. Franciso Arqué (2)
D. Fern.do Maza Arredondo (1)
D. Antonio Frias (3)
D. Francisco Layseca (1)
D. Luis de Martinez (1)
D. Matias Acebal (1)
D. Martin Madan (1)
D. Jose Fernandez (1)
D. Daniel Botefur (1) 41
S.s Cuesta Manz. y herm.s (4)
D. Gaspar Hernand.z
D. Joaquin Madan (2)
D. Manuel Lorio (3)
D. .... Castillo $(1)^{42}$

ParecequePedroBlanco, en un sentidoindirectoheredero de Daniel Botefeur, y más tarde el "Rothschild" de la trata, tenía más suerte con uno de sus primeros viajes entre África y Cuba. Blanco no está en la lista. Desde qué Blanco entró en la trata en Recife ${ }^{43}$, el primer viaje del cual disponemos de huella en las fuentes es el de Julio 1816 a Enero 1817 en el barco negrero PrimeraMonserrat, quétransportaba 162esclavizadosdeGallinas para La Habana.

Primer caso: Juan Ormond vs Antonio Escoto vs Juan Madrazo y estos vs Jacobo Faber (capitalistas contra factores)

Con el primer caso voy a preparar la escena y demostrar que había muy tensos conflictos entre los grandes comerciantes de La Habana (la élite "española", de la cual algunos eran criollos), que a la vez eran armadores, y newcomers cómo Daniel Botefeur, que en cierto sentido era un "africano cosmopolita" cómo he dicho ya, factor y capitán. Por otro lado, había también muy tensos conflictos entre los factores en África (muchas veces personas de color) y los comerciantes y capitanes de Cuba (eso se puede generalizar - se trataba de todos los "americanos" de Cuba, Brasil, Estados Unidos, etc., que en África formaban la parte atlántica).

Hacia el final de 1813 una goleta negrera de Cuba aterrizó en la costa de África, en el Río Pongo en la actual Guinea. El nombre de este buque era Isabel (Ysabel). Su propietario y armador fue Antonio Escoto, un gran comerciante (capitalista) de La Habana. Escoto era un negrero. El capitán del barco (maestre) se llamaba Félix Pujadas.

Los oficiales y la tripulación de este barco eran "blancos" alquilados a un buen sueldo en La Habana (aunque, ciertamente eran una mezcla trasatlánticaqueconsistióprincipalmentede"portugueses",esdecir,también de hombres del Brasil u otras colonias portuguesas y "españoles", es decir también de hombres de Cuba u otras colonias de España). ${ }^{45}$ La"expedición a África" había salido de La Habana en agosto de 1813. Capitán Pujadas habíasidoasignadoadargéneros,commoditiessobretododeCuba(sobre 
contramaestre José Miguel Jotasan [qué] residía en Gallinas como agente para ocuparse del embarque de los esclavos".

26

BORUCKI, Alex; ELTIS, David; WHEAT, David. Atlantic History and the Slave Trade to Spanish America. In: The American Historical Review Vol. 120:2 (2015), p. 433-461.

\section{7}

DORSEY. Seamy Sides of Abolition: Puerto Rico and the Cabotage Slave Trade to Cuba, 1848-73. In: Slavery \& Abolition 19:1 (1998), p. 106-128; ZEUSKE. Rethinking the Case of the Schooner Amistad: Contraband and Complicity after 1808/1820. In: Slavery \& Abolition Vol. 35:1 (March 2014), p. 156-164; ZEUSKE. The Second Slavery: Modernity, mobility, and identity of captives in Nineteenth-Century Cuba and the Atlantic World. In: LAVIÑA; ZEUSKE (eds.). The Second Slavery ..., p. 113-142.

\section{8}

Autos.Testamentaria delDr.Dn.Daniel Botefeur. In: Archivo Nacional de Cuba (ANC), Escribanía de Luis Blanco, legajo (leg.) 405, número (no). 4, f. $9 v$.

\section{9}

Ibidem, f. 10v.

\section{0}

Ibidem, f. 12r-v

31

RODRIGO Y ALHARILLA. Los Marqueses de Comillas 1817-1925. Antonio y Claudio López. Madrid: LID Editorial Empresarial, S.L., 2000; MORGADO GARCÍA, Arturo. Una metrópoli esclavista: el Cádiz de la modernidad. Granada: Editorial Universidad de Granada, 2013.

\section{2}

Había algunos puntos importantes más de la trata: Cienfuegos, Trinidad y Santiago de Cuba, véase: GARCÍA MARTÍNEZ, Orlando. Esclavitud y colonización en Cienfuegos 1819-1879. Cienfuegos:EdicionesMecenas,2008;BELMONTE POSTIGO, José Luis. Notas sobre el tráfico de esclavos en Santiago de Cuba. In: Memorias. Revista Digital de Historia y Arqueología desde el Caribe Vol. 4, núm. 8 (noviembre de 2008), p. 1-18. Disponível em: http://rcientificas. uninorte.edu.co/index.php/memorias/rt/ printerFriendly/400/4769 (27. Jan. 2016)); VENEGAS[DELGADO],Hernán.TrinidaddeCuba. Corsarios, azúcar y revolución en el Caribe. La Habana: Centro de Investigación y Desarrollo de la Cultura Cubana Juan Marinello, 2005; CHAVIANOPÉREZ,LisbethJ.Trinidad.Unahistoria económica basada en el azúcar [1754-1848]. Barcelona: Ediciones Bellaterra, 2014.

\section{3}

ANC, Real Consulado (RC), leg. 180, núm. 18: "Autos principales seguidos por D.n Jacobo Faber, y D.n Cornelio Souchay contra D.n Martin Zavala, y otros sobre cuentas de exped.n de Africa" (1819); "Contrata celebrada entre los Sres. D.n José Ricard, D.n Juan y D.n Antonio O: Farril, D.n Juan Espinoza, y D.n Cornelio Souchay por una parte, y D.n Jacobo Faber por otra, para todo tabaco y ron), pero también algunos textiles y armas, en cambio a cautivos "bozales" en la factoría de esclavos dirigido por John Ormond, también conocido de capitanes y comerciantes hispanoparlantes como Juan Ormond.

Inmediatamente después de su llegada a Río Pongo, el capitán Pujadas entregó el cargamento de su goleta al factor. John Ormond, el hijo de un hombre europeo y una mujer africana, llamado por los nativos Mongo John, de alguna manera entró en conflicto con Pujadas. Un testigo, Jacob Faber de Baltimore, que tenía una residencia en La Habana y una factoría de esclavos en el Río Pongo, más tarde declaró: "que ignora el motivo de la disputa del pardo Ormon, con el maestre de la Goleta, ni menos porq.e resistia mandar abordo y entregar al sobrecargo los citados siervos, y que aunq.e no sabe a cuanto ascendió el numero de negros que dió por el cargamento, vió que recibia mas de ciento".46

Encualquiercaso,Ormondretuvoelcargamentoacordadodecautivos bozales, un poco más de un centenar de personas. Durante el largo tiempo en que la nave estaba ociosa en un brazo del delta del Río Pongo, muchos marineros de la tripulación de la goleta Isabel cayeron enfermos y murieron. Por último, Ormond liberó a los cautivos, probablemente en diciembre de 1813. Con el fin de ser capaz de hacer el viaje de regreso, el capitánPujadastuvoquecontrataranegroslibres(grumetes)deRíoPongo como sustitutos de los marineros que habían muerto. El barco zarpó en enero de 1814, pasando por encima de los bancos de lodo de uno de los brazos del río durante la marea alta y llegó al mar del Atlántico. ${ }^{47}$

No sabemos exactamente cuándo, dónde y por qué la rebelión de los cautivos en la Isabel ocurrió. Lo que sí sabemos es que los negros libres hicieron una alianza con los cautivos (o quizás al revés) - también podría haber lazos familiares o de amigos en ambos lados. La rebelión fue un éxito. Los rebeldes masacraron a todos los blancos. Después de más o menos una semana, la nave aterrizó de nuevo con sus nuevos dueños en la factoría de Ormond en el Río Pongo. Las informaciones de Escoto y el testimonio de Faberen relación a la rebelión coinciden máso menos. En un primermemorandum, conelqueconsiguiólainvestigacióndelcasoarodar en noviembre de 1815, Escoto escribe lo siguiente:"Juan Ormon rebestido [revestido, en el sentidoquéhabía reganadoel control de losesclavizados] de la Autoridad, con que se allaba en aquel parage retubo los Esclavos una porcion de tiempo en su poder, y no los mando abordo asta q.e no le dio gusto y gana, y por cuya de Mora [demora], en aquel parage cayeron en fermo, barios de la Tripulacion y por consiguiente murieron algunos de los marineros, asta yegar el caso de tomar Negros libres de alli para este destino [...] alos cuatro o sinco dias a aber salido la referida Goleta Ysabel de aquel Rio para su destino, bolbio Otrabes de arribada a la misma Costa, de resulta, de aberse le bantado [levantado] los Espresados Marineros Libres, contra el resto de los Blancos de la Tripulacion, ylos Mataron atodos".48 Jacobo Faber afirma sobre la rebelión: "la Goleta Ysabel se hizo ala vela desde Rio Pongo para este Puerto [La Habana] el cuatro o cinco de Enero del año proximo pasado de mil ochocientos catorce, y entre el diezy seis y el diezy sietedel propiomes, volvió de arribada al mismo destino de donde habia salido conducida por los negros libres que se embarcaron en ella en clase de marineros, en cuyo acto se instruyó que estos negros invitaron álos del cargam.to, y levantados en masa pasaron á cuchillo y asecinaron de todos modos alos individuos blancos del equipaje sin dejar uno vivo".49 
Establecer una Factoria en la costa septentrional de Africa en el Puerto de Gallinas, por el termino de dos años contado desde eldia dela llegada de Faber a dcho destino...", in: Ibidem., RC, leg. 192, núm.6:"D.n Jacobo Faber contra D.n Martin Zavala" (1822), f. 7r-8v; ROTH, Günther. Angerona: Fatos e Ficções sobre a Fazenda de Café de Cornelio Souchay e Ursula Lambert em Cuba. In: Sociologia \& Antropologia Vol. 2:4 (2012), p. 211-239.

\section{4}

Observaciones de la Compañía de Cuesta Manzanal y Hermano, referentes al Comercio de NegrosconcincoDocumentosagregadossuf[ec] ha 23 de Nov.re de 1809. In: ANC, RC, leg. 74, no. 2836, La Habana, 23 de noviembre 1809, f. $16 r-22 r$ (texto).

\section{5}

Gale (Samuel). D.n Samuel Gale contra D.n Juan Madrazo sobre cuentas de ciertas expediciones hecha a la Costa de Africa. In: ANC, TC, leg. 196, no. 15 (1816); (esbozo de carta), Madrid, Palacios 9 de Enero de 1820 y no. 2; no. 3: Reclamación de Juan Madrazo. In: Archivo Histórico Nacional (AHN) Madrid, Estado, Trata de negros. Expedientes alfabéticos por el nombre de los barcosapresadosconcargamentodenegros, leg. 8022 (dos cajas). Letra M, 8022/4, no.1.

36

FRANCO.Laoligarquía negrera.In:FRANCO.Op. Cit, p. 142-178.

\section{7}

FUENTE, Alejandro de la. La esclavitud, la ley, y la reclamación de derechos en Cuba:repensando el debate de Tannenbaum. In: FUENTE (coord.). Su "único derecho": los esclavos y la ley. Madrid: Fundación Mapfre| Tavera, 2004 (=Debate y perspectivas. Cuadernos de Historia y Ciencias Sociales, No. 4 (Diciembre 2004)), p. 37-68; FUENTE. Slaves and the Creation of Legal Rights in Cuba: Coartación and Papel. In: Hispanic American Historical ReviewVol. 87:4 (November 2007), p. 659-692.

38

REES, Siân. Sweet Water and Bitter: The Ships ThatStoppedtheSlaveTrade.Durham:University of New Hampshire Press, 2011.

\section{9}

Archivo Histórico Nacional (AHN) Madrid, Estado, Trata de Negros, leg. 8022/4, no. 6: esbozo de reclamación (con informaciones de 1815-1817), Madrid, 10 de Febrero de 1831.

\section{0}

Para uno de estos barcos negreros, la Resurrección ,cargadacon 140 negros Bozalesen el Puerto de Gallinas" existe una huella escrita sobre la reclamación del fondo de los 400000 libras esterlinas, qué London había pagado a Madrid alrededor del tratado de 1817 (abolición de la trata a partir de 1820): reclamación de D. Juan Madrazo del com.[erci]o de la Hav.na. In: AHN, Estado, Trata de Negros, leg. 8022/4, no.1 (esbozo), Madrid, Palacios 9 de Enero de 1820 y lbidem, no. 3. Todavía en 1830 Madrazo reclamaba por las pérdidas de la Resurrección del fondo de los „, cuarenta millones de reales,
Esosignificaquelatripulación,originalmentecompletamente"blanca", incluidos los marineros, oficiales y el capitán (no sabemos si hubo un cirujanoabordo), perecieron durantela rebelión. Fueunatragedia. Unaexplicación de la violencia puede ser encontrada en los trabajos de Sylviane Diouf sobre el odio a los cazadores y traficantes de esclavos que se había acumulado en Senegambia. ${ }^{50}$ Pero la tragedia no había terminado.

Lo que sigue no se corresponde con nuestras ideas habituales sobre resistencia a la trata de esclavos. ${ }^{51}$ Antes de que el barco volviera a la factoríadeOrmond, algunosdeloscautivosrebeldeshuyeron, probablemente los hombres más jóvenes y más fuertes. El rey local percibió un"impuesto de llegada" de 18 cautivos. Los grumetes libres salieron de la nave en la factoría. Arrebataron entre doce y quince de los cautivos por sí mismos, conelfindeutilizarloscomoesclavosovenderloscomocompensación por sus salarios no pagados. Este último es una conjetura, pero muy probable. Jacob Faber dijo lo siguiente sobre el caso: "Juan Ormon bolvió á recojer los negros del cargam.to, a ecepsion de diez y ocho que se tomó el Rey negro Willa Catty en aquel destino de Rio Pongo, y quince mas o menos que sellevaron los marineros negros con el pretexto de hacerse pago de lo que habiantravajado, bienquecreeelexponentequealgunosotrosesclavosse fugaron".52

Luego vino Mongo John Ormond, que hizo lo que realmente provocó la queja de Escoto: encerró a los cautivos ya vendidos (mejor dicho, cambiados por los géneros de Pujadas y Escoto) en sus barracones y luego los vendió de nuevo. E incluso los vendió a buques negreros que también iban a La Habana, como los barcos negreros Atrevido y Junta de Sevilla, de propiedad del comerciante y negrero de La Habana Juan Madrazo. La ira sagrada del traficante sobre la pérdida y la ventaja competitiva injusta se convirtió en la hoja que hendió, por un breve momento, el largo velo negro delas estrategias deocultamientoymarginalización. Ormond dioalgunos de los cautivos a su esposa principal, Geni, que luego los vendió para su propiobeneficio. EndeclaracionesdeFaberpodemosverqueélestabadividido entre su solidaridad con los factores en la costa de África Occidentaly supreocupación porlasprácticascomercialesdeOrmond(Ormondera, por supuesto, un competidor). Faber incluso hizo declaraciones sobre el paradero de la nave:"Que havíendo llegado al Río ó Puerto Bissau el Bergantin español nombrado el Atrevido, sabido esto por Ormon pasó á consultarle al exponente si era practicable ó regular venderle los negros recojidos de la Goleta Ysabel, con el designio de precaver que se huyesen ò muriesen, puesto queel podia reponer otrosiguales en el caso de entregaá su dueño, por cuyo medio se ahorrava tambien de los gastos de una superflua mantencion, y en vista de [ilegible] ... cuando se ocurrió al Puerto de Bissau, ya no estaba alli el citado Bergantin Atrevido, y entonces determinó Ormon dejarlossetentay dosnegros masómenosquehabíallevado,comolohizo en poder de John Pierce, en Rio Nunos".53

Para hacer el trato menos visible, Ormond había intentado en primer lugarvenderloscautivosen Bissau. ${ }^{54}$ Luegovendióa algunoscautivos, que ya habían sido llevados para Río Núñez varias veces, a un tal John Pierce; los otros, a barcos de La Habana. Debido al acuerdo con el barco negrero habanero Junta de Sevilla y con la "half-breed Geni", preguntó Escoto al cirujanoytraficantedeesclavosestadounidense, Dr.Samuel Galé, deCharleston, un"native of the United States of North America, who was responsible for treating the savage Negroes ${ }^{\prime \prime 5}$, para hacer una declaración legal. 
ó sean: cuatrocientos mil Libras Esterlinas que por el tratado de Negros de aquella epoca puso á disposición de V.M. el Gobierno Britanico" "cuarenta y seis mil setenta y siete pesos con ocho reales de plata": Ibidem, no. 4: carta del encargado de Madrazo desde Madrid, 18 de Diciembre de 1830, al rey.

41

Todavía en 1844 los herederos de Botefeur reclamaban una compensación; véase: $\mathrm{AHN}$ Madrid, Trata de Negros, leg. 8025/6, no 3: Carta de Luis Martinez desde Madrid, 14 de octubre de 1844, al secretario de Estado sobre una reclamación de “D. Lorenzo Romay y D. Daniel Botefú" por la Goleta Española Candelaria, la cual había sido capturada en 1815 por cruceros ingleses.

\section{2}

Todavía en 1844 los herederos de Botefeur reclamaban una compensación; véase: $\mathrm{AHN}$ Madrid, Trata de Negros, leg. 8025/6, no 3: Carta de Luis Martinez desde Madrid, 14 de octubre de 1844, al secretario de Estado sobre una reclamación de “D. Lorenzo Romay y D. Daniel Botefú" por la Goleta Española Candelaria, la cual había sido capturada en 1815 por cruceros ingleses.

\section{3}

Pedro entró en Recife pensando hacerse negrero": NOVÁSCALVO,Lino.LibroSegundo.In: NOVÁS CALVO, El Negrero. Biografía novelada de Pedro Blanco Fernández de Trava. Prólogo de Abilio Estévez, Barcelona: Tusquets Editores, 1999, p. 29-200, aquí p. 68; véase también: ANC, Fondo Miscelánea (FM), leg. 11408: "Pedro Blanco y Compañía"y:SURWILLO, Lisa. Monsters by Trade. Slave Traffickers in Modern Spanish Literature and Culture. Stanford: Stanford University Press, 2014

\section{4}

Nota de los Buques que han hido al Africa al comercio de Negros, y regresando des.e el año de 1808 h.ta Oct.e de 1817 con espresion del num.o de cabezas importadas" (Hav.a, Nov.e 22 de 1817). In: ANC, Junta de Fomento, leg. 86 exp. 3506, f. 10r-22r; véase también: AGI Sevilla, Santo Domingo 2207, f. 672r: „Relacion de las Embarcaciones que en el presente mes han entrado en el Puerto con Negros bozales ...., José Sedano, Hab.a, 30 de Marzo de 1816, u.a. Goleta „Moncerrate de Blanco ... [Esp.la]" 5 Piezas Varones, 5 Mulecones Varones, 66 Muleques Varones; 5 Piezas Hembras, 4 Muleconas, 36 Mulecas Hembras; Total 162; Ebd., f. 678r (Mayo de 1816) „Relacion de las Embarcaciones que en el presente mes han entrado en el Puerto con Negros bozales ....' José Sedano, Hab.a, 31 de Mayo de 1816, u.a. Goleta „Eugenia, de Blanco ... [Esp.la]" 35 Piezas Varones, 6 Mulecones Varones, 31 Muleques Varones; 6 Piezas Hembras, 1 Mulecona, 14 Mulecas Hembras; Total 93.

\section{5}

Nota de los Buques que han hido al Africa al comercio de Negros, y regresando des.e el año de 1808 h.ta Oct.e de 1817 con espresion del num.o de cabezas importadas" (Hav.a, Nov.e 22 de 1817). In: ANC, Junta de Fomento, leg. 86 exp. 3506, f. 10r-22r; véase también: AGI Sevilla,
Dr. Galé, que estaba en el Río Pongo como cirujano de un barco negrero y supercargo contratado por Juan Madrazo, declaró: "Que á un Yngles natural de la Bermuda nombrado Styler Edward Lightbourn le entregó el exponente en géneros el valor de cincuenta, y cinco Negros, de los guales le informó áquel al tiempo de la entrega de los Negros, que los guarenta y sinco eran de negocio suyo propio, y los diez restantes pertenecian en propiedad á la Parda, Gení, muger de Ormond - cuyo numero de esclavos en su totalidad eran p.a completar el Cargam.to de la Goleta nombrada Junta de Sevilla". ${ }^{56}$

En otras palabras, Ormond había vendido el resto de los cautivos, que habían sido tomados prisioneros de nuevo desde que la nave rebelde de Escoto volvió a Río Pongo, a un competidor (seguramente a un precio ventajoso). Y Mongo John había dado diez de ellos a su esposa principal Geni (Geny), para que ella también pudiera compartir la ganancia extra. Ambos vendieron con la ayuda de otros traficantes el resto de los cautivos, ya vendidos una vez, a la nave Junta de Sevilla. Esta última navegaba de regreso a Cuba, y en La Habana Escoto reconoció a algunos de "sus" cautivos, posiblemente como resultado de una denuncia hecha por Faber, pero sin duda debido a los carimbos o calimbos (marcas de fuego ${ }^{57}$ ). WilliamTurner, un comerciante negreroinglés de Londres que residía en el Río Pongo en 1814, confirmótodo el asunto una vez más después de queél también había sido interrogado en relación con la queja de Escoto:"Que le parecequeelPardoOrmon los negrosquemandóaPuertoBissaufueronel numero de setenta y dos para venderlos alli, estando cierto que eran delos correspondientesal cargam.to dela GoletaYsabel [...] QueGeny, mugerdel mulato Ormon, vendió dieznegros de los del cargam.to de la GoletaYsabel a un Yngles nat.I de la Bermuda nombrado Styler Edward Lightbourn, los cuales fueron inclusos en los cincuenta y cinco africanos que le vendió á cambio de generos á el sobrecargo de la Goleta Junta de Sevilla, en donde efectivamente fueron embarcados". ${ }^{58}$

La historia continúa. Juan Madrazo, el gran comerciante, dueño de esclavos, y miembro de la oligarquía criolla de La Habana, se tomó la revancha en el advenedizo (y factor) Jacobo Faber, ya queesteúltimo había hecho declaraciones que lo acusan. Madrazo vendió los siete niños esclavos que había Faber había transportado a la Habana en el barco Junta de Sevilla como si fueran sus propios esclavos (de Madrazo). Jacob Faber de hecho había viajado desde el Rio Pongo como un pasajero de pago en la Junta de Sevilla. Si Faber no hubiera testificado en contra de Madrazo, no sólo no tendríamos ninguna información sobre lo que pasó, sino también quesabríamos muchomenos sobre el funcionamiento interno dela tratay las oportunidades de ganancias que ofrecía. Faber había llevado conél, en el viaje desde África hasta La Habana, seis muleques (esclavos adolescentes) y una negrita (probablemente una chica bastante linda) [* llustración: "lista de esclavos de Jacob Faber con nombres africanos" $"$ ]. Para el flete (costos de transporte) para estos esclavos, Faber había pagado 100 pesos por cautivo a Galé. Galé los mantenía y trasportaba como se fueran esclavos del cargamento de Madrazo.

La ventaja de esta disposición era que al pagar el flete el factor no corrió los riesgos de comprar su propia nave y de perderla, ni tenía que pagar por la organización de la expedición, la compra de alimentos, etc. Este tipo de negocio secundario para las guardias, los supercargos y factores, los cirujanos del buque, oficiales, e incluso a veces de los distintos miem- 
Santo Domingo 2207, f. 672r: „Relacion de las Embarcaciones que en el presente mes han entrado en el Puerto con Negros bozales...., José Sedano, Hab.a, 30 de Marzo de 1816, u.a. Goleta "Moncerrate de Blanco ... [Esp.la]" 5 Piezas Varones, 5 Mulecones Varones, 66 Muleques Varones; 5 Piezas Hembras, 4 Muleconas, 36 Mulecas Hembras; Total 162; Ebd., f. 678r (Mayo de 1816) „Relacion de las Embarcaciones que en el presente mes han entrado en el Puerto con Negros bozales ...." José Sedano, Hab.a, 31 de Mayo de 1816, u.a. Goleta „Eugenia, de Blanco .. [Esp.la]" 35 Piezas Varones, 6 Mulecones Varones, 31 Muleques Varones; 6 Piezas Hembras, 1 Mulecona, 14 Mulecas Hembras; Total 93.

\section{6}

Hasta ahora no he encontrado los papeles de la goleta Isabel, pero casi todos los contratos de los capitanes con los oficiales, los marineros, mozos ypages, lossangradores/cirujanos, lostoneleros, despenseros, los cocineros y otros miembros de las tripulaciones (con nombres individuales) se hallan bajo: Protocolos Notariales de Marina y Mayor del Apostadero, No. 436, Tomos: 91 de Marina y 16 del Mayor del Apostadero; fechas extremas de la documentación: Marina 1745 y 1858/ 1859 - 1877 Mayor del Apostadero; véase también: RODRIGUES, Jaime. De costa a costa: escravos, marinheiros e intermediários de tráfico negreiro de Angola ao Rio de Janeiro. São Paulo: Companhia das Letras, 2005.

47

Ibidem, p. 124-125.

48

Memorial. Antonio Escoto al Priory Consules del TribunaldeComercio,LaHabana,8deNoviembre de 1815 [ortografía original]. In: ANC, TC, Leg. 504, no. 32 (1815). Escoto (Antonio)."D.n Antonio Escoto, sobre justificar el numero de negros con que arribo a Rio Pongo en el Africa, la goleta de su propiedad titulada "Isabel"',' f. 1r-2r, aquí f. 1v.

\section{9}

Declaración, Jacobo Faber (con traductor) ante el Consulado, La Habana, 17 de Noviembre de 1817. In: Ibidem, f. 5r-7r, aquí f. 6r; Zeuske. Africa. In: ZEUSKE. Op. Cit, p. 123-191.

50

DIOUF,SylvianeA.FightingtheSlaveTrade:West African Strategies. Athens: Ohio State University, 2003.

51

Declaración,JacoboFaber(contraductor)anteel Consulado, LaHabana, 17 deNoviembre de 1817. In: Ibidem, f. 5r-7r, aquí f. 6r; Zeuske. Africa. In: ZEUSKE. Op. Cit, p. 123-191.

\section{2}

TAYLOR, Eric Robert. If We Must Die. Shipboard Insurrectionsin the Era of the AtlanticSlaveTrade. Baton Rouge: Louisiana State University Press, 2006.

TAYLOR, Eric Robert. If We Must Die. Shipboard InsurrectionsintheEra of the AtlanticSlaveTrade. Baton Rouge: Louisiana State University Press, bros de la tripulación, tales fletes, también llamados pacotilla, eran comúnes, y normalmente los armadores (en este caso Juan Madrazo) hicieron la vista gorda en cuanto a estos negocios de capitanes.

No importa qué forma tomó este negocio ilegal (hubo varias versiones) dentro de la trata de esclavos, los esclavos "pacotilla" estaban mejor alimentados que los cautivos "normales" del cargamento del barco de esclavos.Simorían,eran reemplazados desdelamasa deesclavos privados delos propietarios debuques. Acontinuación, la entrada“muerto"aparece en la lista de esclavos del cargamento normal. Aquí es lo que el negrero Jean Barbot dijo acerca de esta forma de la "inmortalidad" de esclavos pacotilla:"The captain's slaves never die." ${ }^{\prime 60}$ Nuestro caso no se refiere a los esclavospertenecientesalcapitán, peroesclavosaltamentevaloradosque pertenecen a un factor como pasajero del sobrecargo. Pero el capitán tuvo que dar su visto bueno, y seguramente recibió una parte de la ganancia. ${ }^{61}$ Para ver en concreto cómo eso del flete o pacotilla funcionaba, presento documentos del barco negrero Relámpago. Daniel Botefeurera armadory propietario; Juan José Domínguez, capitán del barco. El capitán (y tal vez algunosoficiales) habíancompradoesclavizadosprivados,esdecir,hicieron comerciode pacotilla. Ademástransportabanesclavizadosdeotraspersonas (flete). Todos estos hombres, mujeres y niños adicionales a la lista del cargo oficial eran alimentados y mantenidos a costo del armador Daniel Botefeur. El capitán inscribió todo en un cuaderno privado que llevaba el título "Quaderno delos Negros q.e ban muriendo abordo segun sus marcas Asaver. Julio 18. de 1820".62 Por cada de estos esclavizados privados el capitán recibió 60 pesos. El barco transportaba, repito, al lado de los esclavizados de la lista de cargo oficial, esclavizados privados de ocho hombres de laélite de Bissau, entreellos el famoso Cayetano Nozolini (más tarde gobernador portugués de Bissau). Sobre Nozolini (o Nozzoline) leemos:"Embarca D.n Cayetano Norsolini, de su cuenta y riesgo, tres negros, marca J.D. braso derecho pagando 60 p.s de flete ami cons.[ignacio]n a la Havana". Daniel Botefuer conocía muy bien tanto la gran trata, como los detalles muy feos y crueles de la trata (cómo los castings de cuerpos humanos que tenían que pasar los cautivos arrastrados del interior). YDaniel Botefuer había hecho una parte de su riqueza como capitán con pacotillas $y$ fletes.

Segundo caso: Antonio Escoto vs Juan Ormond y Daniel Botefeur - capitalistas contra factores/ ex-factores y el racismo funcional de la élite tradicional

La élite tradicional de Cuba eran los inventores del racismo funcional (no del racismo científico); un buen ejemplo es Francisco de Arango y Parreño. ${ }^{64}$ La nueva élite negrera-atlántica también fue racista, pero cómo habían actuado muchos años en África como factores y/o capitanes (o cirujanos/médicos) sabían que eso era un territorio"Where the Negroes areMasters" ${ }^{\prime 65}$,yoperabandeotramanera.Pocotiempodespués del primer caso empezó otro en el cual ya vemos Daniel Botefuer y su amigo íntimo Juan Ormond en pleno conflicto contra los "capitalistas" de la Habana, en persona de Antonio Escoto. ${ }^{66}$ Se trataban de viejos rencores, venganzas, cuentas (de expediciones negreras pasadas, de herencias y sobre todo de préstamos qué Ormond había dado a Escoto) - es decir, una mezcla explosiva.Paramencionarsoloalgunospocos delosnegocios:EscotoyOrmond, 
54

Declaración, Jacobo Faber (con traductor) ante el Consulado, La Habana, 17 de Noviembre de 1817. In: ANC, TC, Leg. 504, no. 32 (1815). Escoto (Antonio). “D.n Antonio Escoto, sobre justificar el numero de negros con que arribo a Rio Pongo en el Africa, la goleta de su propiedad titulada "Isabel", f. 5r-7r, aquí f. 6r.

\section{5}

Ibidem, f. 7r.

56

En cuanto a Bissau véase: HAWTHORNE, Walter. Planting rice and harvesting slaves. Transformations along the Guinea-Bissau coast, 1400-1900. Portsmouth: Heinemann, 2003.

\section{7}

Memorial (2०), AntonioEscotoal PrioryConsules del Tribunal de Comercio, La Habana, 14 de Noviembre de 1815. In: ANC, TC, Leg. 504, no. 32 (1815). Escoto (Antonio). “D.n Antonio Escoto, sobre justificar el numero de negros con que arribo a Rio Pongo en el Africa, la goleta de su propiedad titulada "Isabel"',' f. 3r-v, aquí f. 3r.

\section{8}

Declaración, M.rDrSamuelGale (contraducción por parte del traductor del Consulado, D.n Juan Agustin Ferrety), La Habana, 15 de noviembre de 1815. In: Ibidem, f. 4r-v, aqui f. 4r.

59

LA ROSA CORZO, Gabino. Tatuados.

DeformacionesétnicasdeloscimarronesenCuba. La Habana: Fundación Fernando Ortiz, 2011.

60

Declaración, WilliamTurner (con traductor) ante el Consulado, La Habana, 17 de Noviembre de 1817. In: ANC, TC, Leg. 504, no. 32 (1815). Escoto (Antonio). “D.n Antonio Escoto, sobre justificar el numero de negros con que arribo a Rio Pongo en el Africa, la goleta de su propiedad titulada "Isabel"',', f. 7v-8v, aqua f. 8r.

61

ZEUSKE. Africa. In: ZEUSKE, Op. Cit, p. 123-191.

62

ANC, TC, Leg. 30, no. 6 (1820): D.n Daniel Buteffeur contra D.n Juan José Dominguez sobre p.s., f. $35 r-43 r$.

63

Ibidem., f. 40r.

64

ZEUSKE. Arango y Humboldt/Humboldt y Arango. Ensayos científicos sobre la esclavitud. In:GONZÁLEZ-RIPOLL,MaríaDolores\&ÁLVAREZ CUARTERO, Izaskun (eds.). Francisco de Arango y la invención de la Cuba azucarera. Salamanca: Ediciones de la Universidad de Salamanca, 2009 (Aquilafuente, 158), p. 245-260; ZEUSKE. Slavery and Racism in Nineteenth-Century Cuba. In: BERG, Manfred; WENDT, Simon (eds.). Racism in the Modern World. Historical Perspectives on a pesar de su conflicto en cuanto al bergantín Ysabel (arriba), habían cooperado ampliamente, junto con otros negreros, en la expedición del bergantínDosHermanos, deWilmington ${ }^{67}$, asícomoenlasexpediciones delas goletas Dos Amigos y Fabiana (propietario Gaspar Hernández). ${ }^{68}$ En estos negociosatlánticos, Ormond viajabafrecuentementeaCuba.Tenemosque recordar que - saltando al nivel cuantitativo - entre 1811 y 1820 entraron 130371 esclavizados de ambos sexos en La Habana (con un auge de 25841 en 1817) y 11806 a Matanzas (con un auge de 5794 en 1819). ${ }^{69}$

Para no tener que pagar sus deudas a Ormond, Escoto apareció en junio de 1816 con una representación ante el tribunal de comercio: "D.n Ant.o Escoto, vecino y del comercio de esta Plaza, en pleito q.e ha promovido D.n Daniel Botefour como apoderado del Pardo libre Juan Ormon avitante del Rio Pongo en la costa de Africa haciendome reclamaciones de cuentas pend.tes ... paresco ante VZ [SS. Prior y Consules] y digo: Que despues de muchos pasos y conferencias, havenido á efectuarse el verval [verbal] de Ordenanza en q.e el actor hadedicado los dros [derechos] con q.eseconceptua poniedoleyódemandadereconvencion paraq.emereintegre las cantidades q.e me debe y perjuicios de consideracion q.e me ha hecho sentir en la trata de negros en aquel destino en q.e el citado Ormon tienefijada suresidencia.Poresteantesedenteconoserá elTr[ibun]al, q.eel que aparece como actor representado por Botifour es un hombre de color, que vive en aquellas Regiones y en el corazon decierto del Africa sin reconoser ninguna Autoridad ni estar sugeto aninguna Potencia, y si con esta cualidad es apto para conferir personeria, $O$ no lo es, por esta misma razon ... por carecer de los requisitos de la Ley para comparecer en Juicio representando á un individuo no solo avitante del Africa, sino natural de ella [lo que normalmente sólo ocurría con esclavizados]". ${ }^{70}$

Botefeur reacciona de forma muy "cool" (cómo se dijera hoy) muestra su"poder amplio bastante" "71 , quéle ha conferido"John Ormond, residente en ella [Ciudad de la Habana] asociado de D.n Gabriel Pantaleon Encasti interprete auxiliar del R.I Consulado".72 Entonces presenta su"contra-representación" y dice que Ormond y sus parientes en África eran tan ricos que antes Escoto había comido en su casa, y qué se prestó capitales (tal vez en forma de esclavizados) de Ormond ${ }^{73}$ :".q.e Ormon muy lejos de haberle perjudicado á Escoto en su destino del Africa, le ha hecho mil servicios, le ha defendido sus barcos y perdio una factoria q.e lequemaron los ingleses p.r solo haber defendido con las armas un buque de Escoto q.e se querian llevar del propio rio y esta misma conducta ha sido siempre la de Ormoncontodoslosbarcosespañolesmereciendolamayorestimaciondel mismo Escoto hasta llego el instante de pedir su dinero y de venir á esta Ciudad con el fin de cobrarle".74 Escoto había reconocido en una cuenta que debía a Ormond 2925 Pesos. Ormond exigía 8870 Pesos de Escoto. Y ahora viene el racismo funcional. Escoto intentaba - en las palabras de Daniel Botefuer - a ponerle"tacha a su acreedor por la cualidad de pardo q.e vive en el corazon decierto del Africa". 75 Botefeur sigue, qué eso no había impedido a Escoto de dejarse ayudar porOrmond:“habiendo recibido [deOrmond] sus propiedades, habiendolollevadoá comera su mesa, y habiendole dado asiento en su casa". ${ }^{76}$ Esa otra funcionalidad de Botefeur entendían los "SS y Consúl" (Señores y Cónsul) del Consulado de La Habana muy bien. Lo qué le quedaba a Escoto era quejarse de formalidades. Botefeur reaccionaba hábilmente con una"Declaración"777 qué demuestra queél también tenía problemas con las categorías raciales (perolas mane- 
CulturalTransferandAdaption.NewYork/Oxford: Berghahn Books, 2011, p. 105-121.

65

SPARKS, Randy. Where the Negroes are Masters. An African Port in the Era of Slave Trade.

Cambridge [etc.]: Harvard University Press, 2014.

66

D.n Juan Ormond, de la Costa de Africa, C.[uen] ta C.[orrien]te con Ant.o Escoto de este com.o como Albacea de bienes q.e quedaron p.r fallecimiento de J. Fillinghast. In: ANC, TC, leg. 32, no. 15 (1816): Botefeur Daniel. Daniel Botefeur, apoderado de Juan Ormond, contra Antonio Escoto, sobre cuentas mercantiles, Havana, 9 de Mayo de 1816, f. 4v-9r.

67

Ibidem, f. 5 r.

68

Ibidem.

69

"Relacion que se forma por la Administracion de rentas R.s de mi cargo, del número de esclavos deambossexos,importadosenestePuertodesde 1811 á 1820, en q.e se estinguió este tráfico, la cual se saca p.a dirigir á la Superintend.a gral de R.I hacienda en virtud de oficio de 22 de Marzo prox. pasado, á saber" (en esta lista aparecen los barcos y la cifra de esclavizados por barco). In: AGI Sevilla, Cuba, 2169, 1832-1839, Documentación varia (sin foliación); así como: "Estado demonstrativo de la introduccion de negros bozales realizada en este puerto desde el año de 1811 hasta el de 1821 inclusive, en que se estiguió este tráfico, á consecuencia de la Real órden de 9 de Enero de 1818", Havana y Marzo 20 de 1832, firmado por Bernardo Elosúa y Juan Nepom.o de Arocha. In: Ibidem.

\section{0}

Representación de Antonio Escoto. In: ANC, Tribunal de Comercio, leg. 32, no. 15 (1816): Botefeur Daniel. Daniel Botefeur, apoderado de Juan Ormond, contra Antonio Escoto, sobre cuentas mercantiles, f. 9v-11v (La Habana, Junio $26,1816)$ (ortografía original).

71

Poder. In: Ibidem, La Habana, 23 de Abril de 1816, f. $13 r-14 r$.

72

Ibidem, f. $13 r$

73

Representación. In: Ibidem, f. 16r-19v, Daniel Botefeur, La Habana y Julio 24 de 1816.

74

Ibidem, aqui f. 17r.

75

Ibidem, f. $18 v .76$

76

Ibidem.

77

Declaración de Botefeur, La Habana, 8 deagosto jaba funcionalmente en cuanto al espacio de la trata atlántica y africana mejor qué Escoto): "cargando sobre mi la falta q.e en realidad cometio el escribiente de la escribania dando a Ormon el distintivo de D.n p.r la mera costumbre de tratar asi p.r q.e lo merecen cuasi todos los litigantes de este tr[ibun] al ... yo [Botefeur] nunca he dcho [dicho] en la ecribania ni en alguna parte q.e Ormon es blanco ni q.e se llama D.n Juan; bien q.e tampoco es negro como dice el auto [el texto de Escoto] sino mulato ó pardo como lo quieran llamar".78

En este sentido, y en muchos otros, Daniel Botefeur es un pionero de la nueva élite cosmopolita del hidden Atlantic, de la Second Slavery, de la modernidady del capitalismo esclavista de Cuba. Empieza, cómo muchos españoles negreros también (casi todos eran marginales y liberales en su primera juventud), como marginal y radical (lo qué políticamente todavía no sabemos; de todas formas es radical en cuanto al uso de nuevos saberes, prácticasy tecnologías) ytermina cómo invertidorcosmopolita-católico tanto en la trata ilegal cómo en la esclavitud masiva de la economía de plantaciones en Cuba. La muerte lo paró en 1821, pero hay muchos otros en este grupo dinámico.

Tercer caso: Daniel Botefeur vs Roberto Botefeur vs élite tradicional los cosmopolitas de "arriba" y los de "abajo" en conflicto por derechos tradicionales

Los esclavistas ibéricos siempre pensaban de si que no eran tan "capitalistas" cómo los esclavistas de otras religiones, sobre todo inglesesy neerlandeses. Esto es un tópico desde Brasil hasta Cuba, de Portugal hasta España, desde Simón Bolívar hasta Francisco de Arango. Daniel Botefeur como un pionero del nuevo capitalismo atlántico cosmopolita y católico (recuerdan qué antes era luterano) luchó de una forma real y simbólica contraesos derechostradicionales (Arangolosllamaba"loscuatroconsuelos"de los esclavizados en Cuba; sobre todo la llamada coartación). Procesaba contra su propio esclavo de confianza Roberto Botefeur; pero no fue sólo eso - procesaba también contra la construcción legal y tradicional de la esclavitud en Cuba antes de $1815 .^{80}$ Era un pionero de la Second Slavery. Lo interesante es - lo digo de antemano - Daniel Botefuer tuvo éxito en el caso concreto (y tal vezen cuanto al clima de auto compras/coartación por parte de los esclavizados por algunos años), pero no en general.

Primero,DanielBotefuercomoabogadoexperimentado,incriminaba un robo de 2000 mil pesos por parte de su esclavo Roberto (de su"caja de hierro en que deposito mi caudal efectivo"). ${ }^{81}$ Luego habla de la verdadera razón de su conflicto con su esclavos "de confianza": "se me han confirmado mis sospechas de que el negro Roberto es el ladron, por que su muger ha d.cho en estos dias à sus compañeras, que tiene para libertarse ella, el marido, y cuatro hijos".82 Roberto Botefeur quería coartación. Cómo era un hombre también muy experimentado y cosmopolita, apareció en el despacho del alcalde ordinario de La Habana y dictaba una "representación": „Robin Botefaud [sic] moreno esclavo de D.n Daniel Botefaud con el mayor rendimiento à V[os] dice: que [en] muchas ocasiones ha deseado salir del poder de su amo, y este le ha exigido 4000. p.s por el, la mujer y tres hijos menores, lo que no le ha permitido lograrlo por lo escandaloso de este precio; pero conciliando ... tiene determinado libertarse, contribuyendo à su amo amas de las quince onzas que la tiene el demas dinero q.e llene 
de 1816. In: Ibidem, f. 22r-v.

78

Ibidem, f. 22r-22v.

ANC, Escribanía de Daumy, leg. 370, no. 1 (1818): Daniel Botefeur, contra su esclavo Roberto sobre hurto (lafoliación es parcialmente doble, desde f. 4 r aparece cómo "4 [y] 5").

\section{0}

FUENTE. La esclavitud, la ley, y la reclamación de derechos en Cuba: repensando el debate de Tannenbaum. In: Op. Cit, p. 37-68.

81

Petición deDanielBotefeur, LaHabana, Enero 29 de 1818. In: ANC, Escribanía de Daumy, leg. 370, no. 1 (1818): Daniel Botefeur, contra su esclavo Roberto sobre hurto, leg. $1 \mathrm{r}-2 \mathrm{r}$.

\section{2 \\ Ibidem, f. 1v.}

\section{3}

Representación al Señor Alcalde Ordinario, La Habana y Enero 31 de 1818. In: ANC, Escribanía de Daumy, leg. 370, no. 1 (1818): Daniel Botefeur, contra su esclavo Roberto sobre hurto, f. 4r-v.

\section{4}

D. Botefeur al Tribunal. In: Ibidem, La Habana, 26 de febrero de 1818, f. $6 r$-v.

\section{5}

Interrogatorio cerrado. In: ANC, Escribanía de Daumy, leg. 370, no. 1 (1818): Daniel Botefeur, contra su esclavo Roberto sobre hurto, La Habana, 26 de febrero de 1818, f. 7r-9r.

86

Ibidem f. 7r-9r, aqui 7r. su precio, regulado por un Perrito [un síndico]: en esa virtud AV suplica, ... se haga saber ... á su amo D.n Daniel, manifieste por ... cuanta cantidad estima por la libertad al exponiente ..., La Hab.a y En.e 31 de 1818 ------A ruego del esclavo". ${ }^{83}$

El próximo 26 de febrero de 1818 Daniel Botefeur escribe por su parte al tribunal y pide "que se haga comparecer á mi esclavo ante el S.or Asesory absuelva los particulares contenidos en el interrogatorio serrado que pongo en manos de S[u] S[eño]ria".84 Daniel Botefeur había confeccionado una Lista de preguntas con el título"Interrogatorio [cerrado] por dondedebeexaminarseal negro RobertoesclavodeD.nDanielBotefeur ${ }^{\prime \prime}{ }^{\prime 25}$ Esa lista nos deja reconocer mucho de los pormenores de la vida diaria de un esclavo de casa bajo casi pleno control de su amo. Su amo está básicamente luchando toda agency de su esclavo:

"Primeramente diga como es verdad que lo compré en la costa de Africa en el año de mil ochocientos [1800!!], y desde entonces lo apliqué á mi servicio. ${ }^{86}$

2 Ytt. Como tambien es cierto que lo puse á aprehender el oficio de herrero en una fortaleza inglesa q.e está, en la misma costa de Africa, y en efecto aprehendió bien este oficio y arte.

3 Ytt. Como lo es que situado yo en esta Ciudad y antes de casarme, tenia yo una herreria en mi propia casa, en la que p.r mi cuenta, y a mi vista trabajaba el q.e absuelve.

4 Ytt. Como tambien es verdad q.e luego q.e me case, quité aquella herreria, y apliqué al q.e absuelve como antes a mi servicio domestico.

5 Ytt. Como tambien es cierto q.e le entregué las llaves de mis almacenes de azucar, café, y otros efectos q.e guardaba en aquellos.

6 Ytt. Como tambien es verdad q. era el único esclavo de /[f. 8v] mi confianza, y p.r este motivo estaba encargado de barrer y asear diariam. te el cuarto escritorio, y atender la cama del dependiente q.e alli dormia, p.r cuyo fin tomaba libremente la llave para hacer este servicio en dicho escritorio, donde entraba y salia sin embarazo.

7 Ytt. Diga como es verdad q.e en dicho cuarto escritorio, q.e está en el descanso de la escalera, tengo una caja grande de hierro en que guardo todo mi dinero.

8 Ytt. Diga como es verdad que habrá ocho meses mas o menos q.e lo llamé un dia para q.e viera y examinara la dicha caxa y su maquina, y en efecto abrió, desarmó la cerradura, untó aceyteá sus piezas, limpiandolas, cuya operacion executó delante de mi, hasta volver á armar la cerradura y dexarla como estaba.

9 Ytt. Como es cierto q.e todos los domingos la daba yo ocho reales [1 pesos de a ocho] para cigarros, los que gastaba en este objeto y en su muger é hijos mis esclavos.

10 Ytt. Como tambien es cierto q.e yo le visto á el y á su muger con todo aseo, q.e cuanto me ha pedido siempre tanto le he facilitado: que le headvertidoconstantementeq.emepidiesequantonecesitara,yen/[f.9r] efecto siempre la daba las cosas q.e me pedia.

11 Ytt. Diga como es cierto q.e yo tenia prevenido q.e si alguna persona le hacia algun regalo, especialmente de dinero, o si lo adquiria p.r algun otro motivo justo, me lo dixese, me lo enseñare, no para cogerlo yo, sino para saber con q.e titulo ó razon habia adquirido.

$12 \mathrm{Ytt}$. Como es verdad que nunca me dió aviso de que tuviere dinero 
alguna; ycomo tambien le es q.e preguntandoleyo una vezsi tenia dinero, me contestó que no, haciendome la reconvencion de q.e ¿como podia èl tener dinero?

$13 Y t t$. Diga como es cierto que habrá un año y medio que se me desaparecieron dospares depantalones decasimirnuevos deltodo;yq.epreguntandole yo p.r ellos me contestó que los habia tomado un cuñado mio.

14 Ytt. Como tambien es verdad que algun tiempo despues de esta ocurrencia, y durmiendo el q.e contesta en una casa extramuros, dondeyo tenia unos negros bosales, lo sorprendíuna mañana en queestaba vestido con un par de aquellos pantalones.

15 Ytt. Como es verdad q.e habiendolo yo mandado á una diligencia desde dicha casa extramuros á la q.e tengo en esta Ciudad, al presentarse el q.e absuelve á mi muger vestido con los mismos pantalones, dixo ésta sorprehendida, esos son los pantalones que decías tu haber tomado mi hermano.

16 Ytt. Diga como es cierto que habiendome dicho, habrá tres ó /[f. $9 \mathrm{v}]$ cuatro meses, q.e queria ganar jornal, me le niegué à ello diciendole que no estaba en necesidad de tal cosa.-

17Ytt. Diga como es cierto que habiendome dicho q.e tenia quien lo comprara, le di papel p.r tres dias, el q.e me devolvió el q.e contesta al cabo de media hora, pidiendome perdon.

18 Ytt. Diga quien le ha dado dinero para libertarse á si mismo, á su muger, y a sus hijos segun lo ha dicho en el Tribunal.

19 Ytt. Diga de donde ha adquirido tanta cantidad como necesita para libertarse él, su muger y cuatro hijos.

20 Ytt. Exprese claramente, y sobre esto llamo la atencion del S.or Asesor el origen de la adquisición del dinero, los medios de haberlo proporcionado, el tiempo q.e hace q.e lo este juntando, la cantidad q.e tenga, quien es su depositario en el dia, quien lo ha sido hasta aqui, sobre lo cual no se omitira circunstancia alguna.

21 Ytt. Diga como es cierto q.e compréála muger del q.eabsuelveen la costa de Africa, bosal, q.e en mi poder se casaron, y q.e los dos no han conocido otro amo q.e yo.

Ytt [sin numeración] Diga como es verdad q.e nunca lo he separado de mi lado que siempre ha estado destinado á mi servicio, q.e nunca ha ganado jornal, y q.e ha sido el criado de todas mis confianzas. Havana y Febrero 26 de 1818.

\section{Daniel Botefeur}

87

Ibidem, f. 7r-9r.

88

Ibidem, f. 9r.

89

Declaración del esclavo Roberto, La Habana, 2 de Marzo de 1818. In: ANC, Escribanía de Daumy, leg. 370, no. 1 (1818): Daniel Botefeur, contra su esclavo Roberto sobre hurto, f. 9r-13r.

\section{D.r Sebastian Fernandez de Velasco" ${ }^{\prime \prime 7}$}

La fuente también nos da una idea de lo qué paso después. Robin Botefuer tiene que pasar a un Depósito de esclavos (no sabemos a cuál) y de allí tiene que aparecer delante del tribunal, jurar y responder (lo que demuestra que un esclavo en ciertos casos si podía tener personalidad jurídica): "compareció ante el Asesor el Moreno Roverto esclavo de D.n. Daniel Botefour de quien se recibio juram.to".88 La huella escrita de su voz la encontramos en una "Declaración", hecha en La Habana, 2 de Marzo de $1818: 89$

"[respuestas a las preguntas de la lista arriba] Al prim.o que es exacto que sólo su S.or lo compro en la costa de Africa, y que no / [f. 9v] save 
si fue el año de ochocientos pero si que era muy joven habiendolo á su servicio desde su adquisicion

Al segundo:que el sugeto q.e tenia por amo quandolo compró el q.e interroga lo tenia puesto a aprender el oficio de herrero en una fortaleza Ynglesa cituada en la costa de Africa y que continuo en su aprendizaje en la misma Fortaleza por Ord.ny designa.n de su actual S.or hasta perfeccionarse en el oficio" ${ }^{\prime 90}$

La respuestas de Robin Botefeur en cuanto a la tercera y cuarta pregunta fueron:"es cierto el contenido de la pregunta" ${ }^{\prime 1}$, lo que deja reconocer qué el esclavizado tenía conocimientos legales:

"Al quinto: que su amo no le encargo la llabes de sus almacenes como supone en la pregunta aunq.e alguna ves se las franqueaba p.a / [f. 10r] sacarsealgunos efectos lo que executabaá su presencia debolvíendosela inmediatam.te que serraba

Al sexto: que si merecia la confianza de su S.or y que entraba diariam.teenelquartoescritorioaseandoloylimpiandoloaunquenotendiala cama donde dormia el dependientepuesestolo hacia una neg.a [negra] su compañera, que para este servicio tomaba librem.te la llabe de la referida pieza [cuarto] en la q.e entraba y salia sin embarazo pero siempre á vista de su S.or ó del depend.te

Al septimo:que es cierto que en el precitado quarto escritorio esta la caxa grande de hierro donde el .../[f. 10v] ...guarda todo su dinero

Al octavo: que es cierto todo el contenido de la pregunta

Alnoveno:quees cierto q.esu S.orledabatodoslos domingos un peso p.a cigarros pero lo guardaba p.a juntar el cap.[ital] de su libertad ó la de su hijo si acaso falleciera sin haverlo ganado jamas

Al decimo: que es cierto que su S.or le tenia prevenido que quando alguna otra persona le hiciera algun regalo de dinero ó si el declarante adquiria algunos reales por algunos medios ilicicizo [iilicitos?] se le abisare è instruyese, no para apropiarselo sino para saver la legitimidad de suadquisicion pero que como en cierta ocacion le presentase quatro p.[eso]s y se quedare con / [f. 11 r] tres entregandole solo uno [i]!, no le bolvio á enseñar otracanti.[dad]delasqueadquiriadejandodecumpliraquel presepto[eso significa qué Robin no siguió a los avisos de su amo - eso es importante para la realidad del llamado peculium (peculio) - MZ].

Al duodecimo: que despues q.e le presento los cuatro p.s de que ha hecho referencia en su ant.r contesta.n no le dio abiso [aviso] ni le comunico que hubiese alg.n dinero y que su S.or no le pregunto jamas ni tenia dinero con cuyo motivo no tubo que hacerle la reconvencion que indica la pregunta

Al decimo tercio: que es cierto que habra tiempo de mas de un año que su S.or le pregunto por dos pares de pantalones de casimir, q.e habian desaparecido, y que le contesto q.e ignoraba su paradero siendo falso el que hubiese asegurado de que los tuvo un cuñado del q.e interroga

Al decimo quarto: que le encontro con /[f. 11v] unos pantalones de mesclilla picarosquehabia desechadoelmismoq.epreguntanosiendode los pares que le habian robado ó desaparecido

Al decimo quinto: que es falso el cont.o de la pregunta [iun esclavizado valiente!]

Al decimo sexto: que es cierto que habrá dos o tres meses, que manifesto asu S.orquequeriaganarjornalòlovendiesehabiendolecontestado 
q.e no tenia necesidad de semejante cosa

Al decimo septimo: que es cierto que pidió a su S.or pap.I [papel - uno de los "cuatro consuelos"] para buscar amo no por que entonces tubiese qui.[e]n lo comprase, pero q.e habiendole expresado el mismo su S.or que si salia / [f. 12r] de la parte afuera de su casa no bolvia á entrar le debolvio el pap.l q.e ya le habia ministrado pidiendole perdon

Al decimo octabo: que solo tiene dinero para libertarse asi mismo y no á su muger è hijos: que lo habia reunido con los pesos que su amo le daba todos los Domingos, y con otras partidas pequeñas de dinero que le franqueabanalgunosamigosdel propiosuS.orencuyoservicioseocupaba algunas veces por mandato de aquel

Al decimo nono: que se remite á su anterior contesta

Al vigesimo: que tendra un capital de / [f. 12v] quinientos p.s poco mas ò menos el que ha podido reunir en los terminos y por los medios q.e lleba inaugurados desdequebinoá esta Ciudad [18años con más o menos 40-50 pesos - es probable - MZ]: que aquella suma la tiene depositadas, doscientoscinquentay cinco p.sy una onza mas en un dependiente de que le interroga nombrado D.n José y el resto lo tiene entregado á una señora blanca, que vive en el Barrio del Monserrate cuyo nombre ignora

Al vigesimo primo: que es cierto el con.t de la pregunta

Alvigesimo nono [sic, en vez de secundo]:queigualmenteesciertoy respondequelo que ha declaradoes la verdad no cargo de sujuramento se le leyo y espuso estar conforme que es mayor de veinte y cinco a.[demá]s no fir/ [f. 13r] mo por que dijo no saver ... el S.or Asesor de que doy fe

\section{Benito [escribiente]}

\section{Antemi}

\section{José Rafael Dequesa}

Declaracióndelesclavo Roberto,LaHabana,2de Marzo de 1818, en: Ibidem., aquí f. 9v-13r.

93

Ibidem, f. 14r-14v.

94

lbidem, f. 19v.

\section{Gro [?] dos acistencias [testigos] ${ }^{492}$}

Conlaayudadeunblancoquesabeescribir, RobertoBotefeurmanda además una petición al Tribunal:"Roberto Botefoure en los autos para q.e suamoD.nDanielleconceda la libertad porel precioq.e contribuya siendo moderado, ó por el q.e se le pone con dispocicion del Tr.[ribun]al con su acostumbrado respeto dice: que el asunto está parado enteramente: ha sesado el amo en su acalorada intentona, y parece se quiere dexar dormir el asunto p.a meditarse otra ... [no legible], pero como el q.e habla firme en su propuesta esta decidido á adquirir su libertad ... en el concepto de q.e el exponente [Roberto] usara de los derechos/[f. 14v] en el orden q.e la ley señala y como es de ... cuya gracia espera recibir. Habana y Marzo 9 de 1818 ... Pedro José Esquivél".93

Daniel Botefeur se pone furioso. Lo que aparente más le molesta es tanto la agencia de Roberto como la ayuda de su aliado blanco, Pedro José Esquivel (quién es él que escribe para el esclavizado):“D.n Pedro Esquivel persona que tomo á su cargo la agencia del negro".94

Del interrogatorio cerrado no se da ninguna afirmación de los cargos del amo - ni mucho menos una evidencia. Roberto niega haber robado el dinero. Él, cómo dijo, sólo tenía dinero para el rescate de su persona, que había ahorrado durante los 18 años de su esclavitud bajo el amo Daniel 
95

Ibidem, f. 18r-24r, La Habana 4 de Marzo de 1818, Daniel Botefur, aqui f.19r.

96

Ibidem, f. 18r-24r, La Habana 4 de Marzo de 1818, Daniel Botefur, aqui f. 20r

97

Protesta, Daniel Botefeur. In: Ibidem, f. 42r-50r, La Habana, 27 de Julio de 1818, aqui f. 42r-43r.

98

Ibidem, f. 42r-50r, aqui f. 48v.
Botefeur. Roberto Botefeur requiere su tasación, es decir la fijación oficial de la suma para el ahorramiento. Botefeur retrasa ahora el caso y sólo responde a una solicitud del Síndico. Escribió varias protestas y trata de llevar los dueños de esclavos a su lado. El comerciante negrero cosmopolita, seguramente liberal, amo de esclavos así como de plantaciones, protesta contra la tradición legal de ahorramiento, sobre todo contra la posibilidad dedeponerdineroconterceros:"Quemedios derobarnóproporcionaálos esclavos, principalmentedomesticos, lafacilidaddehallarquienlésguarde su urto [hurto]! ¡A que peligro nó estamos expuestos los amos al ver la facilidad con que impugnemente se prestan personas blancas á depositar dineroencantidadgruesaópequeñaq.elesentregan losesclavos deotros! ¿Qual és [para el] S.or Alcalde la seguridad domestica, si a casos semejantes al mio nó se pone inmediatamente la mano en un dinero depositado contra toda razon y dr.o, y admitido contra la prohivision de las leyes?"95

Daniel Botefeur sigue:"y por ultimo és del mayor interes de aquella [más arriba en f. 20r: "la seguridad domestica atacada de los esclavos"] él que el esclavo no se liberte con lo que roba á su S.or, y lo és tambien el que no se patrosine por el concepto de libertad un hurto domestico probado yá en medio de las dificultades que casi generalmente se presentan para probar los hechos de esta clase. Esto és dar aliento á los esclavos para q.e delincan, y yó estoi resuelto por el bien publico y por el mio particular á seguir esta causa hasta los pies del Soberano".96

Roberto Botefeur tenía que quedarse en el Depósito de Esclavos, donde los esclavos son obligados a trabajar duro para el Estado. Cómo el síndico (un abogado de pobres) está inclinado a darle razón al esclavizado, cómo es costumbre en la esclavitud tradicional de Cuba, Daniel Botefeur repite sus protestas:"[en las explicaciones del síndico] se sostiene la ilegal pretension de que le otorgue á mi esclavo la carta de ahorro por su justo precio, sinatenderáqueestácompetentementecalificadoel hurtoqueme ha hecho del dinero con que solicita redimirse ... Por mi desgracia, y quizas para la de todos los amos, se ha considerado en esta causa que el interes público en patrocinar el de un /[f. 42v] esclavo que solicita la libertad, útil y provechosa á él solo, es mucho mayor que el de reprimir en todos ellos la facilidad de cometer un delito, castigar c.o en mio el hurto que me ha hechoparaobteneraquella.Baxotanequivocadoprincipio(hablorespetuoso) se protege expresamente en el auto .... la causa del negro Roberto, $y$ despreciandose la mia que es la de todos [los amos de esclavos] ... [f. 43r] De que un esclavo se redime o no del cautiverio no se le sigue a nadie, ni un bien ni un mal, mas que á él solo, pero de que un esclavo robe á su propio señor o á otro gualquiera [sic] para exhibir el precio de su libertad, yq.e ésta se le conceda, ó al menos sea defendida por la autoridad pública, dexando impugne la criminalidad de aquel, resulta un grave daño público contrael sagrado derecho de propiedad, yotro públicocontrala seguridad individual[...]".97 Y sigue produciendo"evidencias":"El peso que le daba los domingos lo gastaba en el resto de la semana en cigarros que fumaba con exceso, y en pan y leche para sus hijos".98

Cómo Roberto sigue en el Depósito de Esclavos por más de un año, Daniel Botefeur protesta una y otra vez qué su esclavos allá no trabajan para él y exige un procedimiento acelerado.

El síndico procurador general emite un juicio en el caso de Roberto Botefeur - en pro del esclavizado. Dice que el "robo" es sólo una suposición, nada se probó, dubio pro reo, etc.: "la alegacion de just.[ici]a se sirva 
El Sindico Procurador Gral en los autos seguidos por el negro Roberto Botefeur sobre libertad, La Habana, Marzo 17 de 1819. In: Ibidem, f. 86r-90r, aquíf. $89 \mathrm{v}$.

100

Petición, D. Botefeur, La Habana, Abril 20 de 1819. In: Ibidem, f. 91r-108v.

101

Juicio, D.n Joséde Matienzo, alcaldeordinario de esta [La Habana], Junio 11 de 1819. In: Ibidem, f. $111 v-113 r$, aqui f. $112 \mathrm{v}-113 r$.

102

Ibidem, f. $111 \mathrm{v}-113 \mathrm{r}$, aqui f. $112 \mathrm{v}$. citar para definitiva, y en aquella fallar, q.e se le debe otorgar à Roberto su carta de ahorro por su justa tazac.n." ${ }^{\prime 99}$ Daniel Botefeur debe emitir la carta de ahorro para Roberto Botefeur. Parece que el esclavo cosmopolita ha ganado el pleito.

Daniel Botefeur presenta objeción en una larga petición. ${ }^{100} Y$ pasa lo inesperado: el alcalde le da razón a él y anula el juicio de síndico. El alcalde, contra todos las costumbres tradicionales"declara que el esclavo no há provado el esecial fundam.to de su detencion y demanda, y que el amo le ha hecho en cuanto basta. De sus legítimas y perentorias excepion y defensas; en cuya virtud debia absolver, y en efecto absuelva á este de la demanda, imponiendo á aquel perpetuo cilencio [sic]; y en consecuencia mandar q.e se extrahiga /[f. 113r] al ciervo del deposito en que se halla, y se entregue á su Señor, á quien se la previene que no le castigue ni le maltrate por causa de este pleyto". ${ }^{101}$ El juicio del alcalde se basa en suposiciones y conjeturas:"que el repetido negro pudo haber sido el autor del robo hecho á su amo en su propia casa, forzando con destreza la cerradura de la caxa de hierro donde este depositaba su caudal efectivo, por la maestria é inteligencia que aquel propio ha confiado tener en el oficio de herrero, y prevalido asímismo de la confianza q.e se le dispensaba por todos los de la casa; bienen [vienen] a persuadir hasta la evidencia q.e la cantidad exibida por Roberto para su redencion és indudablem.te una parte de la robada á D.n Daniel Botefeur: y atendiendo por ultimo al interes de la causa pública en q.e los esclavos no adquieran su libertad, sino por medio honestos, justos y legítimos, y no con dinero ilicita y criminalmente adquirido".102

El síndico no contradice a la sentencia del Alcalde.

Breve conclusión

Lo penúltimo que sabemos de Roberto Botefeur es lo qué Daniel Botefeur escribealTribunal, yeso confirma que el amo teme el cosmopolitismo"deabajo"del esclavizado:"Temo que mi esclavo emprenda fuga con la noticia del pronunciamiento final, pues este es el único arbitrio que le queda para evadir el cumplim.to de la sentencia y eximirse de volver á mi poder:esunnegrodemasiadoastutoymuyrebelde:entiendeperfectam.te el idioma ingles y el español: tiene todavia dinero oculto del q.e me robó; $y$ toda esto le facilita la fuga, para tomar quizas partido entre los piratas, entrequieneshaymuchosnegros, quesonadmitidosfrancam.tep.raquellos; y p.r todas estas consideraciones se ha de servir V. mandar q.e inmediatamente y ántes todas cosas se me facilite p.r la Essma la órden necesaria para extraer á mi esclavo del poder del depositario, y tenerlo en mi casa con las seguridades debidas, hasta que logre venderlo, como estoy tratando de hacerlo, p.r ser de justicia ut supra. Daniel Botefeur/ Dr. Sebastian Fernandez de Velasco, Hab.a Jun. 22 de 1819". ${ }^{103}$

Y lo absolutamente último es que el esclavizado no es tan"rebelde", sino que se quedó en la casa de su amo.

Daniel Botefeur lo libera por su testamento:"que el moreno Roberto mi esclavo luego que yo falliece se le otorgue por mi albacea carta de livertad". ${ }^{104}$

Daniel Botefeur, el cosmopolita "africano", había ganado todos los casosquehemosexpuesto(el primerosóloindirectamente);sobretodohabíaganadocontraun"negrodemasiadoastutoymuyrebelde[qué]entiendeperfectamenteelidiomainglesyelespañol [yseguroquevariosidiomas 
105

FINCH, Aisha K. Rethinking Slave Rebellion in Cuba. La Escalera and the Insurgencies of 1841-1844. Chapel Hill: The University of North Carolina Press, 2015.

106

TARDIEU, Jean-Pierre. "Morir o dominar". En torno al reglamento de esclavos en Cuba (18411866). Madrid: Iberoamericana; Frankfurt am Main: Vervuert Verlag, 2003 (Acta Coloniensia. Estudios Ibéricos y Latinoamericanos, eds. Hans Jürgen Prien y Michael Zeuske, VII). de Africa]",cómo el mismo lo expresó. En realidad el esclavizado Roberto era muy civilizado, sabía ejercer un oficio y era un cosmopolita"desde abajo". La victoria de Daniel Botefeur - con aplauso de otros negreros (sobre todo) y otros amos de esclavos, así como de la burocracia local-colonial - abre una épocadeendurecimientodelaesclavitudenCuba;unaépocaprácticamente sin leyes que la limiten; por lo menos hasta 1844 (el año de la famosa conjuración de la Escalera ${ }^{105}$ y un nuevo código, el reglamento de esclavos ${ }^{106}$ ).

De lo que sólo los esclavistas de la élite criolla tradicional más hábiles y experimentados se dan cuenta (cómo Francisco de Arango) es quela victoria de los nuevos capitalistas atlánticos-cosmopolitas sobrelos derechos tradicionales delosesclavizadosestambiénunavictoriadeestos sobre ellos mismos.

El negrero y cosmopolita Daniel Botefeur fue un pionero del hidden Atlantic.

Referencias bibliográficas

\section{Fontes documentais}

Archivo Histórico Nacional, Madrid (AHN)

(Esbozo de Carta), Madrid, Palacios 9 de Enero de 1820 y no. 2; no. 3 : Reclamación de Juan Madrazo. In: AHN Madrid, Estado, Trata de negros. Expedientes alfabéticos por el nombre de los barcos apresados con cargamento de negros, leg. 8022 (dos cajas). Letra M, 8022/4, no. 1 .

(Esbozo de reclamación (con informaciones de 1815-1817)), Madrid, 10 de Febrero de 1831. In: AHN Madrid, Estado, Trata de Negros, leg. $8022 / 4$, no. 6 .

Carta del encargado de Madrazo desde Madrid, 18 de Diciembre de 1830, al rey. In: AHN, Estado, Trata de Negros, leg. 8022/4, no. 4.

Carta de Luis Martinez desde Madrid, 14 de octubre de 1844, al secretario de Estado sobre una reclamación de "D. Lorenzo Romay y D. Daniel Botefú". In: AHN Madrid, Trata de Negros, leg. 8025/6, no 3.

Reclamación de D. Juan Madrazo del com.[erci]o de la Hav.na. In: AHN, Estado, Trata de Negros, leg. 8022/4, no.1 (esbozo), Madrid, Palacios 9 de Enero de 1820.

Archivo General de Indias, Sevilla (AGI)

"Estado demonstrativo de la introduccion de negros bozales realizada en este puerto desde el año de 1811 hasta el de 1821 inclusive, en que se estiguió este tráfico, á consecuencia de la Real órden de 9 de Enero de 1818", Havana y Marzo 20 de 1832, firmado por Bernardo Elosúa y Juan Nepom.o de Arocha. In: AGI Sevilla, Cuba, 2169, 18321839, Documentación varia (sin foliación).

„Relacion de las Embarcaciones que en el presente mes han entrado en el Puerto con Negros bozales ...", José Sedano, Hab.a, 30 de Marzo de 1816. In: AGI Sevilla, Santo Domingo 2207, f. 672r.

"Relacion que se forma por la Administracion de rentas R.s de mi cargo, del número de esclavos de ambos sexos, importados en este Puerto desde 1811 á 1820, en q.e se estinguió este tráfico, la cual se saca 
p.a dirigir á la Superintend.a gral de R.I hacienda en virtud de oficio de 22 de Marzo prox. pasado, á saber". In: AGI Sevilla, Cuba, 2169, 1832-1839, Documentación varia (sin foliación).

Representación [copia original] deSebastian Martin de Rojas [apoderado]. In: Archivo Generals de Indias (AGI), Ultramar, 35, n.15, Madrid, ... de Agosto de 1820: Exped.te sobre que a la Casa Social Titulada Cuesta Manzanal y hermanos en la Isla de Cuba se le conceda el permiso para poder transportar 1600. negros que tenia comprados para sus hacienda, antes del tratado hecho con el Rey de Inglaterra, Madrid 5. de Oct.re de 1820, f. 609r-614r.

Archivo Nacional de Cuba, La Habana (ANC)

ANC, Escribanía de Daumy, legajo (leg.).370, número (no.) 1 (1818): Daniel Botefeur, contra su esclavo Roberto sobre hurto, La Habana, 26 de febrero de 1818.

Autos.Testamentaria del Dr.Dn.Daniel Botefeur.In:Archivo Nacional deCuba (ANC), Escribanía de Luis Blanco, legajo (leg.) 405, número (no). 4.

Autos principales seguidos por D.n Jacobo Faber, y D.n Cornelio Souchay contra D.n Martin Zavala, y otros sobre cuentas de exped.n de Africa (1819). In: ANC, Real Consulado (RC), leg. 180, núm. 18.

Carta de D. Botefeur, Habana, $1^{\circ}$ de Junio de 1819. In: Ibidem., f. 115r-115v. Contrata celebrada entre los Sres. D.n José Ricard, D.n Juan y D.n Antonio O: Farril, D.n Juan Espinoza, y D.n Cornelio Souchay por una parte, y D.n Jacobo Faber por otra, para Establecer una Factoria en la costa septentrional de Africa en el Puerto deGallinas, porel termino de dos años contado desde eldia dela llegada de Faber a dcho destino. In: ANC, TC, Leg. 192, no. 6 (1822).

Copia original del testamento [de Daniel Botefeur], Matanzas, 9 de Junio de 1821. In: Autos. Testamentaria del Dr. Dn. Daniel Botefeur. In: ANC, Escribanía de Luis Blanco, legajo (leg.) 405, número (no).4, folio (f.), 9 recto $(r)-11$ verso $(v)$.

Copia original del testamento, Matanzas, 9 de Junio de 1821. In: ANC, Escribanía de Luis Blanco, leg. 405, no. 4, f., 9r-11v

D. Botefeur al Tribunal, La Habana, 26 de febrero de 1818. In: ANC, Escribanía de Daumy, leg. 370, no. 1 (1818): Daniel Botefeur, contra su esclavo Roberto sobre hurto, f. 6r-v.

D.n Jacobo Faber contra D.n Martin Zavala (1822). In: ANC, RC, leg. 192, núm.6.

D.n Juan Ormond, de la Costa de Africa, C.[uen]ta C.[orrien]te con Ant.o Escoto de este com.o como Albacea de bienes q.e quedaron p.r fallecimiento de J. Fillinghast. In: ANC, TC, leg. 32, no. 15 (1816): BotefeurDaniel.DanielBotefeur, apoderadodeJuanOrmond,contra Antonio Escoto, sobre cuentas mercantiles, Havana, 9 de Mayo de 1816, f. $4 v-9$ r.

Declaración de Botefeur, La Habana, 8 deagosto de 1816.In:ANC, Tribunal de Comercio, leg.32, no. 15 (1816): Botefeur Daniel. Daniel Botefeur, apoderado de Juan Ormond, contra Antonio Escoto, sobre cuentas mercantiles, f. 22r-v.

Declaración del esclavo Roberto, La Habana, 2 de Marzo de 1818. In: ANC, Escribanía de Daumy, leg. 370, no. 1 (1818): Daniel Botefeur, contra su esclavo Roberto sobre hurto, f. 9r-13r.

Declaración del esclavo Roberto. La Habana, 2 de Marzo de 1818. In: 
Archivo Nacional de Cuba (ANC), Escribanía de Daumy, legajo (leg.). 370, no. 1 (1818): Daniel Botefeur, contra su esclavo Roberto sobre hurto, (folio) f. 9 (recto) r-13r.

Declaración,JacoboFaber (contraductor) anteel [Tribunaldel] Consulado, Havana, November 17, 1817.In:ANC,Tribunal deComercio, Leg.504, no. 32 (1815). Escoto (Antonio).“D.n Antonio Escoto, sobre justificar el numero de negros con que arribo a Rio Pongo en el Africa, la goleta de su propiedad titulada "Isabel'"', f. 5r-7r.

Declaración,JacoboFaber(contraductor)anteelConsulado,LaHabana, 17 de Noviembre de 1817. In: ANC, TC, Leg. 504, no. 32 (1815). Escoto (Antonio).“D.n Antonio Escoto, sobre justificar el numero de negros con que arribo a Rio Pongo en el Africa, la goleta de su propiedad titulada "Isabel'"', aquí f. $6 r$

Declaración, M.r Dr Samuel Gale (con traducción por parte del traductor del Consulado, D.n Juan Agustin Ferrety), La Habana, 15 de noviembre de 1815. In: ANC, TC, Leg. 504, no. 32 (1815). Escoto (Antonio).“D.n Antonio Escoto, sobre justificar el numero de negros con que arribo a Rio Pongo en el Africa, la goleta de su propiedad titulada "Isabel'"', f. 4r-v.

Declaración, William Turner (con traductor) ante el Consulado, La Habana, 17 de Noviembre de 1817. In: ANC, TC, Leg. 504, no. 32 (1815). Escoto (Antonio). “D.n Antonio Escoto, sobre justificar el numero de negros con que arribo a Rio Pongo en el Africa, la goleta de su propiedad titulada "Isabel'"', f. 7v-8v.

El Sindico Procurador Gral en los autos seguidos por el negro Roberto Botefeur sobre libertad, La Habana, Marzo 17 de 1819. In: ANC, Escribanía de Daumy, leg. 370, no. 1 (1818): Daniel Botefeur, contra su esclavo Roberto sobre hurto, f. 86r-90r.

Faber(Jacobo):"Cuadernodecuentasproducidasáconsecuenciadel pleito seguido en el Real Consulado, entre D.n Jacobo Faber y D.n Martín Zavala". In: ANC, TC, Leg. 186, no. 23 (1823).

Faber (Jacobo): "D.n Jacobo Faber, contra D.n Martin Zabala". In: ANC, TC, Leg. 178, no. 6 (1822), f. 7r-8v (también: ANC, Real Consulado (RC), leg. 192, núm.6).

Faber (Jacobo): "D.n Jacobo Faber, contra D.n Martin Zabala”. In: ANC, TC, Leg. 192, no. 6 (1822).

Faber (Jacobo):"Jacobo Faber, contra Juan Madrazo, sobre pesos de ciertas cuentas de negros bozales". In: ANC, TC, Leg. 184, no. 13 (1815).

Gale (Samuel).D.n Samuel Gale contra D.n Juan Madrazo sobre cuentas de ciertas expediciones hecha a la Costa de Africa. In: ANC, TC, leg. 196, no. 15 (1816).

Interrogatorio cerrado. In: ANC, Escribanía de Daumy, leg. 370, no. 1 (1818): Daniel Botefeur, contra su esclavo Roberto sobre hurto, La Habana, 26 de febrero de 1818, f. 7r-9r.

Juicio, D.n José de Matienzo, alcalde ordinario de esta [La Habana], Junio 11 de 1819. In: ANC, Escribanía de Daumy, leg. 370, no. 1 (1818): Daniel Botefeur, contra su esclavo Roberto sobre hurto, La Habana, 26 de febrero de 1818, f. 111v-113r, aqui f. 112v-113r.

List (original), written August, 21, 1815, Rio Pongo (en inglés). In: ANC, TC, leg. 184, no. 13 (1815). Faber (Jacobo): "Jacobo Faber, contra Juan Madrazo, sobre pesos de ciertas cuentas de negros bozales", f. $4 r$ (photo image). 
(Lista con los nombres de los negreros, números de barcos perdidos, su valor y el valor de los esclavizados (en pesos de a ocho), 1816). In: ANC, RC, leg. 86/3506: Expediente No. 964 sobre cumplimiento de la R.I orden que previene se formalice y remita una justificación de los buques y numero de negros apresados por los ingleses para establecer la reclamación competente al Gobierno de S.M.B (Marzo 21 de 1816), f. 43r.

Memorial ( $\left.2^{\circ}\right)$, Antonio Escoto al Priory Consules delTribunal de Comercio, La Habana, 14 de Noviembre de 1815. In: ANC, TC, Leg. 504, no. 32 (1815). Escoto (Antonio). “D.n Antonio Escoto, sobre justificar el numero de negros con que arribo a Rio Pongo en el Africa, la goleta de su propiedad titulada "Isabel"',' f. 3r-v.

Memorial. Antonio Escoto al Prior y Consules del Tribunal de Comercio, La Habana, 8 de Noviembre de 1815 [ortografía original]. In: ANC, TC, Leg. 504, no. 32 (1815). Escoto (Antonio). “D.n Antonio Escoto, sobrejustificar el numero de negros con que arribo a Rio Pongo en el Africa, la goleta de su propiedad titulada "Isabel f. $1 \mathrm{r}-2 \mathrm{r}$.

Nota de los Buques que han hido al Africa al comercio de Negros, y regresando des.eel año de $1808 \mathrm{~h}$.ta Oct.e de 1817 conespresion del num.o de cabezas importadas" (Hav.a, Nov.e 22 de 1817). In: ANC, Junta de Fomento, leg. 86, exp. 3506, f. 10r-22r.

Observaciones delaCompañía deCuesta Manzanaly Hermano, referentes al Comercio de Negros con cinco Documentos agregados su f[ec] ha 23 de Nov.re de 1809. In: ANC, RC, leg. 74, no. 2836, La Habana, 23 de noviembre 1809, f. 16r-22r (texto).

Pedro Blanco y Compañía. In: ANC, Fondo Miscelánea (FM), leg. 11408.

Petición de Daniel Botefeur, La Habana, Enero 29 de 1818. In: ANC, Escribanía de Daumy, leg. 370, no. 1 (1818): Daniel Botefeur, contra su esclavo Roberto sobre hurto, f. $1 \mathrm{r}-2 \mathrm{r}$.

Petición, D. Botefeur, La Habana, Abril 20 de 1819. In: ANC, Escribanía de Daumy, leg. 370, no. 1 (1818): Daniel Botefeur, contra su esclavo Roberto sobre hurto, f. $91 \mathrm{r}-108 \mathrm{v}$.

Poder, La Habana, 23 de Abril de 1816: In: ANC, Tribunal de Comercio, leg. 32, no. 15 (1816): Botefeur Daniel. Daniel Botefeur, apoderado de Juan Ormond, contra Antonio Escoto, sobre cuentas mercantiles,f. $13 r-14 r$.

Protesta, Daniel Botefeur, La Habana, 27 de Julio de 1818. In: ANC, Escribanía de Daumy, leg. 370, no. 1 (1818): Daniel Botefeur, contra su esclavo Roberto sobre hurto, f. 42r-50r.

Protocolos Notariales de Marina y Mayor del Apostadero, No. 436, Tomos: 91 de Marina y 16 del Mayor del Apostadero; fechas extremas de la documentación: Marina 1745 y 1858/ 1859 - 1877 Mayor del Apostadero.

"Quaderno delos Negros q.e ban muriendo abordo segun sus marcas Asaver ------ Julio 18. de 1820". In: ANC, TC, Leg. 30, no. 6 (1820): D.n Daniel Buteffeur contra D.n Juan José Dominguez sobre p.s., f. 35r-43r.

ANC, Escribanía de Daumy, leg. 370, no. 1 (1818): Daniel Botefeur, contra su esclavo Roberto sobre hurto (la foliación es parcialmente doble, desde f. $4 \mathrm{r}$ aparece cómo "4 [y] 5").

Representación al Señor Alcalde Ordinario, La Habana y Enero 31 de 1818. In: ANC, Escribanía de Daumy, leg. 370, no. 1 (1818):Daniel Botefeur, 
contra su esclavo Roberto sobre hurto, f. 4r-v.

Representación de Antonio Escoto, La Habana, Junio 26, 1816) (ortografía original). In: ANC, Tribunal de Comercio, leg. 32, no. 15 (1816): BotefeurDaniel.DanielBotefeur,apoderadodeJuanOrmond, contra Antonio Escoto, sobre cuentas mercantiles, f. 9v-11v.

Bibliografia

ARAUJO, Ana Lucia. Les représentations de l'esclavage dans les gravures des relations Voyage pittoresque et historique au Brésil (1834) de Jean-Baptiste Debret (1768-1848) et Deux Années au Brésil (1862), deFrançois-AugusteBiard (1799-1882).In:Canadian Journal of Latin American and Caribbean Studies 59, no. 30 (2005), p. 161-183.

Archivo Histórico Nacional (AHN) Madrid, Sección de Estado, Correspondencia entre la Capitanía General de Cuba y la Primera Secretaría de Estado sobre la introducción de esclavos (1817-1873), 2 vols., Madrid: AHN, 1995 (mecanografiado, comp. León-Tello, P.).

BELMONTE POSTIGO, José Luis. Notas sobre el tráfico de esclavos en Santiago de Cuba. In: Memorias. Revista Digital de Historia y Arqueología desde el Caribe Vol. 4, núm. 8 (noviembre de 2008), p. 1-18.Disponível em: http://rcientificas.uninorte.edu.co/index.php/ memorias/rt/printerFriendly/400/4769 (27. Jan. 2016)).

BERBEL, Márcia; MARQUESE, Rafael; PARRON, Tâmis. Escravidão e política: Brasil e Cuba, c. 1790-1850. São Paulo: Hucitec, 2010.

BORUCKI, Alex; ELTIS, David; WHEAT, David. Atlantic History and the Slave Trade to Spanish America. In: The American Historical Review Vol. 120:2 (2015), p. 433-461.

CHAVIANO PÉREZ, Lisbeth J.Trinidad.Una historia económica basada en el azúcar [1754-1848]. Barcelona: Ediciones Bellaterra, 2014.

COGGESHALL, George. Chapter IX: Voyage to St. Bartholomew, St. Thomas, Santa Cruz and Porto Rico, in the Years 1830 and 1831. In: COGGESHALL,Voyages to various parts of the world:made between the years 1800 and 1831; selected from his ms. journal of eighty voyages. New York: D. Appleton \& Company, 1853 ( $2^{\text {nd }}$ edition), p. 241-273.

CONNEAU, Theophilus. Chapter $66^{\text {th }}$. Description of Gallinas. In: Conneau. A Slaver's Log Book, or 20 Years Residence in Africa. The Original 1853 Manuscript by Captain Theophilus Conneau. Englewood Cliffs: Prentice Hall, 1976, p. 246-248, aquí p. 246 (1836-1837).

DORSEY.SeamySides of Abolition:PuertoRicoand theCabotageSlaveTrade to Cuba, 1848-73. In: Slavery \& Abolition 19:1 (1998), p. 106-128.

Escoto, José Augusto, collector. José Augusto Escoto Cuban history and literature collection, ca. 1574-1922 (inclusive), ca. 1715-1850 (bulk). In:Houghton Library, Harvard University, Cambridge, Mass (=Escoto Papers:http://oasis.lib.harvard.edu/oasis/deliver/ hou00236(15de Mayo 2015).

FINCH, Aisha K. Rethinking Slave Rebellion in Cuba. La Escalera and the Insurgencies of 1841-1844. Chapel Hill: The University of North Carolina Press, 2015.

FRANCO, José Luciano. Los mongos de la costa de África. In: Franco, Comercio clandestino de esclavos, La Habana: Editorial de Ciencias 
Sociales, ${ }^{3} 1996$, p. $178-202$.

FUENTE, Alejandro de la. La esclavitud, la ley, y la reclamación de derechos en Cuba: repensando el debate de Tannenbaum. In: Fuente (coord.). Su "único derecho": los esclavos y la ley. Madrid: Fundación Mapfre| Tavera, 2004 (=Debate y perspectivas. Cuadernos de Historia y Ciencias Sociales, No. 4 (Diciembre 2004)), p. 37-68.

. Slaves and the Creation of Legal Rights in Cuba: Coartación and Papel. In: Hispanic American Historical Review Vol. 87:4 (November 2007), p. 659-692.

GARCÍAMARTÍNEZ,Orlando.EsclavitudycolonizaciónenCienfuegos18191879. Cienfuegos: Ediciones Mecenas, 2008.

GATES JR., Henry L. Were There 'Mulatto' Slave Traders? 100 Amazing Facts about the Negro: A father-son story illustrates dynamics of the trade in humans. Disponível em: http://www.theroot.com/articles/ history/2013/10/mulatto_slave_traders_who_were_they.html(20. February 2016)).

GESTRICH, Andreas; SCHULTE BEERBÜHL, Margrit (eds.). Cosmopolitan Networks in Commerce and Society 1660-1914. London: German Historicallnstitute,2011 (GermanHistoricallnstituteLondonBulletin SupplementNo.2.Disponívelem:http://www.ghil.ac.uk/fileadmin/ redaktion/dokumente/bulletin/GHIL\%20Bulletin\%20Supplement\%20 2\%20\%282011\%29.pdf (31 enero de 2016))).

GRADEN, Dale T. O envolvimento dos Estados Unidos no comércio transatlântico de escravos para o Brasil, 1840-1858. In: Afro-Ásia, Salvador, n.35 (2007), p. 9-35.

. U.S. Involvement in the Transatlantic Slave Trade to Cuba and Brazil. In: Graden. Disease, Resistance, and Lies. The Demise of the Transatlantic Slave Trade to Brazil and Cuba. Baton Rouge: Louisiana State University Press, 2014, p. 12-39.

HAIR, Paul E.; JONES; LAW, Robin (eds.). Barbot of Guinea. The Writings of Jean Barbot on West Africa 1678-1712, 2 vols. London: Hakluyt Society, 1992.

HANCOCK, David J. Slaving: Bance Island's 'General Rendevous'. In: Hancock.CitizensoftheWorld.Londonmerchantsandtheintegration oftheBritishAtlanticcommunity, 1735-1785.Cambridge:Cambridge University Press, 1995, p. 174-220.

HAWTHORNE,Walter.Plantingriceandharvestingslaves.Transformationsalong the Guinea-Bissau coast, 1400-1900. Portsmouth: Heinemann, 2003.

HORNE, Gerald. O sul mais distante. Os Estados Unidos, o Brasil e o tráfico de escravos africanos. São Paulo: Companhia das Letras, 2010.

JOHNSON, Sherry. The Rise and Fall of Creole Participation in the Cuban Slave Trade, 1789-1796. In: Cuban Studies 30 (1999), p. 52-75.

JONES, Adam. From Slaves to Palm Kernels. A History of the Galinhas Country (West Africa) 1730-1890. Wiesbaden: Steiner Verlag, 1983 (Studien zur Kulturkunde; 68).

KRIKLER, Jeremy, A Chain of Murder in the Slave Trade: A Wider Context of the Zong Massacre. In: International Review of Social History Vol 57:3 (December 2012), p. 393-415.

LAVIÑA, Javier; ZEUSKE (eds.). The Second Slavery. Mass Slaveries and ModernityintheAmericasandin the AtlanticBasin.Berlin;Muenster; NewYork:LITVerlag, 2014(Sklavereiund Postemanzipation/Slavery and Postemancipation/ Esclavitud y postemancipación; Vol. 6). 
LAWRANCE, Benjamin. A Full Knowledge of the Subject of Slavery': The Amistad, Expert Testimony, and the Origins of Atlantic Studies. In: Slavery \& Abolition Vol. 36:2 (2015), p. 298-318.

. Amistad's Orphans: An Atlantic Story of Children, Slavery, and Smuggling. New Haven and London: Yale University Press, 2014. . La Amistad's 'Interpreter' Reinterpreted: James Kaweli Covey's DistressedAtlanticChildhoodandtheProductionofKnowledgeabout Nineteenth-Century Sierra Leone.In:Schwarz, Suzanne;Lovejoy, Paul E. (eds.). Slavery, Abolition and the Transition to Colonialism in Sierra Leone. Trenton: Africa World Press, 2014, p. 215-256.

LIBERATO, Carlos F. Money, Cloth-Currency, Monopoly, and Slave Trade in the Rivers of Guiné and the Cape Verde Islands, 1755-1777. In: Eagleton, Catherine; Fuller, Harcourt; Perkins, John (eds.). Money in Africa. London: The British Museum, 2009, p. 9-19.

MARQUES, Leonardo. A participação norte-americana no tráfico transatlântico de escravos para os Estados Unidos, Cuba e Brasil. In: Historia:Questões\&Debates,Curitiba,no.52 (jan./jul.2010),p.91-117.

MILLER, Joseph C., The Problem of Slavery as History. A Global Approach. New Haven: Yale University Press, 2012.

MORGADO GARCÍA, Arturo. Una metrópoli esclavista: el Cádiz de la modernidad. Granada: Editorial Universidad de Granada, 2013.

MOUSER, Bruce L. Trade, Coasters, and Conflict in the Rio Pongo from 1790 to 1808. In: Journal of African History 14 (1973), p. 45-64. . (ed.). Guinea Journals: Journeys into Guinea-Conakry during the Sierra Leone Phase, 1800-1821. Washington: University Press of America, 1979.

. Théophilus Conneau: The Saga of aTale. In: History in Africa 6 (1979), p. 97-107.

. The Baltimore/Pongo Connection: American Entrepreneurship, ColonialExpansionism,orAfricanOpportunism?In:Thelnternational Journal of African Historical Studies Vol. 33, No. 2 (2000), p. 313-333. . A History of Rio Pongo: Time for a New Appraisal. In: History in Africa 37 (2010), p. 329-354.

. American Colony on the Rio Pongo: The War of 1812, Continuing Slave Trade, and Plans for a Settlement of African Americans, 18101830. Trenton: Africa World Press, 2014.

MURRAY, David. Odious Commerce: Britain, Spain and the Abolition of the Cuban Slave Trade. Cambridge: Cambridge University Press, 1980.

NEEDELL, Jeffrey D. The Abolition of the Brazilian Slave Trade in 1850: Historiography, Slave Agency and Statemanship. In: Journal of Latin American Studies, Vol. 33, no. 4 (2001), p. 681-712.

NOVÁS CALVO, Lino. Libro Segundo. In: Novás Calvo, El Negrero. Biografía novelada de Pedro Blanco Fernández de Trava. Prólogo de Abilio Estévez, Barcelona:Tusquets Editores, 1999, p. 29-200.

O'BRIEN, William Patrick. McCoy, Waldo, and Smith. A Case Study in International Trade. In: O'Brien. Merchants of Independence: International Trade on the Santa Fe Trail, 1827-1860. Kirksville: Truman State University Press, p. 145-167.

O'MALLEY, Gregory. The Intercontinental Slave Trade of British America, 1619-1807. Chapel Hill:The University of North Carolina Press, 2014. ORTEGA, José Guadalupe. Cuban Merchants, Slave Trade Knowledge, and the Atlantic World, 1790s-1820s. In: Colonial Latin American 
Historical Review Vol. 15:3 (2006), p. 225-251.

PAQUETTE, Robert L.; Dorsey, Joseph C., The Escoto Papers and Cuban Slave Resistance. In: Slavery \& Abolition Vol. 15:3 (December 1994), p. 88-95.

PARK, Mungo. Chapter XIX. In: Park. Travels in the Interior Districts of Africa Performed under the Direction and Patronage of the African Association, in the Years 1795, 1796, and 1797. London: Printed byW. Bulmer and Company, 1800 (4 $4^{\text {th }}$ edition), p. 227-238.

PÉREZ MURILLO, María Dolores, El pensamiento esclavista del Tribunal de Comercio de la Habana (año de 1841). In: Solano, Francisco; Guimerá, Agustín (eds.). Esclavitud y derechos humanos. La lucha por la libertad del negro en el sigloXIX. Madrid:Consejo Superior de Investigaciones Científicas, 1990, p. 407-414.

REDIKER, Marcus. Origins. In: Rediker. The Amistad Rebellion: An Atlantic Odyssey of Slavery and Freedom. New York: Viking, 2012, p. 13-63.

REES, Siân. SweetWater and Bitter:The ShipsThat Stopped the SlaveTrade. Durham: University of New Hampshire Press, 2011.

RODRIGO Y ALHARILLA, Martín. Los Marqueses de Comillas 1817-1925. AntonioyClaudioLópez.Madrid:LIDEditorialEmpresarial,S.L.,2000. . From Periphery to Centre: Transatlantic Capital Flow, 1830-1890. In: Leonard, Adrian; Pretel, David (eds.). The Caribbean and the Atlantic World Economy. Circuits of trade, money and knowledge, 1650-1914. London:Palgrave Macmillan, 2015 (Cambridge Imperial and Post-Colonial Studies Series), p. 217-237.

RODRIGUES,Jaime.Decostaacosta:escravos, marinheiroseintermediários detráficonegreirodeAngolaaoRiodeJaneiro.SãoPaulo:Companhia das Letras, 2005.

ROSA, Fernando. The Portuguese in the Creole Indian Ocean: Essays in Historical Cosmopolitism. Basingstoke/ New York: Palgrave Macmillan, 2015.

ROTH, Günther. Angerona: Fatos e Ficções sobre a Fazenda de Café de Cornelio Souchay e Ursula Lambert em Cuba. In: Sociologia \& Antropologia Vol. 2:4 (2012), p. 211-239.

SAUPIN, Guy (ed.). Africains et Européens dans le monde atlantique XVeXIXe siècle. Rennes: Presses Universitaires de Rennes, 2014.

SHERIFF, Abdul. Dhow Cultures of the Indian Ocean: Cosmopolitanism, Commerce and Islam. New York: Columbia University Press, 2010.

SPARKS, Randy. Where the Negroes are Masters. An African Port in the Era of Slave Trade. Cambridge [etc.]: Harvard University Press, 2014.

SURWILLO, Lisa. Monsters by Trade. Slave Traffickers in Modern Spanish Literature and Culture. Stanford: Stanford University Press, 2014.

TARDIEU,Jean-Pierre."Morirodominar".Entornoalreglamentodeesclavos en Cuba (1841-1866). Madrid: Iberoamericana; Frankfurt am Main: Vervuert Verlag, 2003 (Acta Coloniensia. Estudios Ibéricos y Latinoamericanos, eds. Hans Jürgen Prien y Michael Zeuske, VII).

TOMICH,DaleW.The,SecondSlavery':Bonded Laborand theTransformations of the Nineteenth-century World Economy. In: Ramírez, Francisco O. (ed.).RethinkingtheNineteenthCentury:ContradictionsandMovement. New York: Greenwood Press, 1988, p. 103-117.

.Through the Prism of Slavery. Labor, Capital, and World Economy. Boulder [etc.]: Rowman \& Littlefield Publishers, Inc. 2004.

.The Order of Historical Time:The Longue Duree and Micro-History. In:Lee, Richard (ed.).The Longue Duree andWorld-Systems Analysis. 
Albany: State University of New York Press, 2012, p. 9-33.

TOMICH, Dale \& ZEUSKE, Michael (eds.). The Second Slavery: Mass

Slavery, World-Economy, and Comparative Microhistories, 2 vols.

Binghamton:BinghamtonUniversity,2009(=specialissue;Review:A Journal of the Fernand Braudel Center, Binghamton University XXXI, n. $2 \& 3,2008)$.

VENEGAS [DELGADO], Hernán. Trinidad de Cuba. Corsarios, azúcar y revolución en el Caribe. La Habana: Centro de Investigación y Desarrollo de la Cultura Cubana Juan Marinello, 2005.

YÁÑEZ,César.Losnegociosultramarinosdeunaburguesíacosmopolita.Los catalanes en las primeras fases de la globalización, 1750-1914. In: Revista de Indias Vol. LXVI, núm. 238 (2006), p. 679-710.

ZEUSKE, Michael, Arango y Humboldt/Humboldt y Arango. Ensayos científicos sobre la esclavitud. In: González-Ripoll, María Dolores \& Álvarez Cuartero, Izaskun (eds.). Francisco de Arango y la invención de la Cuba azucarera. Salamanca: Ediciones de la Universidad de Salamanca, 2009 (Aquilafuente, 158), p. 245-260.

.Slavery and Racism in Nineteenth-Century Cuba.In:Berg, Manfred; Wendt, Simon (eds.). Racism in the Modern World. Historical Perspectives on Cultural Transfer and Adaption. New York/ Oxford: Berghahn Books, 2011, p. 105-121.

. Rethinking the Case of the Schooner Amistad: Contraband and Complicity after 1808/1820. In: Slavery \& Abolition Vol. 35:1 (March 2014), p. 156-164.

.The Second Slavery:Modernity, mobility, and identity of captives in Nineteenth-Century Cuba and the Atlantic World. In: Laviña, Javier; Zeuske(eds.).TheSecondSlavery.MassSlaveriesandModernityinthe Americas and in the Atlantic Basin. Berlin; Muenster; New York: LIT Verlag, 2014, p. 113-142.

. Africa. In: ZEUSKE. Amistad. A Hidden Network of Slavers and Merchants. Princeton: Markus Wiener, 2015, p. 123-191.

.Sklavenhändler,Negrerosund Atlantikkreolen.EineWeltgeschichte des Sklavenhandels im atlantischen Raum [Comerciantes de esclavos, negreros y Criollos del Atlántico. Una historia global del tráfico negrero en el espacio atlántico]. Berlin/ Boston: de Gruyter Oldenbourg, 2015. 